\title{
RIVER CHANNEL GEOMETRY AND RATING CURVE ESTIMATION USING HEIGHT ABOVE THE NEAREST DRAINAGE
}

\author{
Xing Zheng, David G. Tarboton, David R. Maidment, Yan Y. Liu, Paola Passalacqua
}

Ph.D. Student (Zheng) and Professor (Maidment, Passalacqua), Center for Research in Water Resources, University of Texas at Austin,10100 Burnet Rd., Austin, Texas 78758; and Professor (Tarboton), Civil and Environmental Engineering Department, Utah State University, Logan, Utah; and Senior Research Programmer (Liu), CyberGIS Center, University of Illinois at Urbana-Champaign, Urbana, Illinois (E-Mail/Zheng: zhengxing@utexas.edu)

ABSTRACT: River channel geometry is an important input to hydraulic and hydrologic models. Traditional approaches to quantify river geometry have involved surveyed river cross-sections, which cannot be extended to ungauged basins. In this paper, we describe a method for developing a synthetic rating curve to relate flow to water level in a stream reach based on reach-averaged channel geometry properties developed using the Height Above Nearest Drainage (HAND) method. HAND uses a digital elevation model of the terrain and computes the elevation difference between each land surface cell and the stream bed cell to which it drains. Taking increments in water level in the stream, HAND defines the inundation zone and a water depth grid within this zone, and the channel characteristics are defined from this water depth grid. We apply our method to the Blanco River (TX) and the Tar River (NC) using 10-meter terrain data from the USGS 3DEP Elevation dataset. We evaluate the method's performance by comparing the reachaverage stage-river geometry relationships and rating curves to those from calibrated HEC-RAS models and USGS gage observations. The results demonstrate that after some adjustment, the river geometry information and rating curves derived from HAND using national-coverage datasets are comparable to those obtained from hydraulic models or gage measurements. We evaluate the inundation extent and show that our approach is able to capture the majority of the FEMA 100-year floodplain.

KEY TERMS: hydrologic terrain analysis; river geometry; rating curve; HAND; flooding This is the peer reviewed version of the following article:

Zheng, X., D. G. Tarboton, D. R. Maidment, Y. Y. Liu and P. Passalacqua, (2018), "River Channel Geometry and Rating Curve Estimation Using Height above the Nearest Drainage," JAWRA Journal of the American Water Resources Association, 54(4): 785806, http://doi.org/10.1111/1752-1688.12661.

which has been published in final form at http://doi.org/10.1111/1752-1688.12661. This article may be used for non-commercial purposes in accordance with Wiley Terms and Conditions for Use of Self-Archived Versions. A read only online version is available from Wiley at https://rdcu.be/2gOo. 


\section{INTRODUCTION}

Flooding is the most threatening natural disaster worldwide considering the fatalities and property damage it causes. It makes up about $40 \%$ of all natural disasters worldwide and causes about half of all natural hazard fatalities (Noji, 1991; Ohl et al., 2001). Under a changing climate, the magnitude (Knox, 1993) and frequency (Milly et al., 2002) of floods may increase significantly, which, together with growing population and expanding urbanization, results in more serious and frequent flood hazards. For the 136 coastal cities across the world alone, the annual losses due to flooding have been projected to increase to $\$ 52$ billion per year by 2050 (the 2005 estimate was $\$ 6$ billion) considering socio-economic impacts alone, and this number could even reach $\$ 1$ trillion if other factors are considered (Hallegatte et al., 2013).

Inundation maps show the spatial extent of flooding and play an important role in emergency response during flood events (Apel et al., 2009; Maidment, 2016). Accurately mapping flood inundation extent requires a comprehensive description of the geometry of the channel and floodplain, since flooding water is routed by the river fluvial system (Maidment, 1992). Traditional approaches to quantifying river geometry rely on measurements of river cross sections. Attempts to combine many independently developed local HEC-RAS models have failed due to variations in model development, overlaps in cross sections from one local model to another, and gaps in coverage of some streams (Zheng, 2015).

Other approaches to obtaining channel geometry without introducing cross sectional information have also been investigated, such as hydraulic geometry relationships (Leopold et al., 1953), and remotely sensed imagery inference (Pavelsky and Smith, 2008). Andreadis et al., (2013) developed a simple global river bankfull width and depth database using a regression relationship between bankfull discharge, drainage area and hydraulic geometry characteristics. Yamazaki et al., (2014) applied an algorithm that calculates the distance from a remotely-sensed water body edge to the river centerlines following flow directions, to produce the Global Width Database for Large Rivers (GWD-LR) using the SRTM Water Body Database and the HydroSHED (Hydrological data and maps based on SHuttle Elevation Derivatives at multiple scales) 
flow direction raster. Both bankfull width and effective river width without islands were computed for river channels between 60S and 60N (Yamazaki et al., 2014).

A so-called first fine-resolution, continental-scale river centerline and width database, the Landsat-derived North American River Width (NARWidth) dataset, has been developed (Allen and Pavelsky, 2015). It includes rivers ranging from approximately the fourth to the tenth Strahler stream order, the width of which are wider than 30 meters at annual mean discharge. Some limitations are found in these river geometry datasets: first, the resolution of the river network is not high enough to use in flooding studies of local streams. Taking Texas as an example, there are 20,004 HydroSHEDS flowlines in Texas, while the number of flowlines is 101,240 in the medium-resolution National Hydrograph Dataset Plus (NHDPlus) used in the National Water Model. Therefore, numerous local streams, which are critical during flood events, are not detected in the existing global river width and depth database. Additionally, only the bankfull width and depth are provided instead of a continuous relationship between stage height and channel properties, which limits the applicability of this dataset for inundation mapping.

While prior research using remotely sensed data or statistical approaches to investigate river geometry and rating curves has resulted in useful insights and approaches (Getirana et al., 2013; Paris et al., 2016; Garambois et al., 2017), these methods do not extract information from the actual terrain. Relationships obtained from statistical analyses are thus insufficient to depict the unique physiographic characteristics of each channel and remotely-sensed imagery only captures part of a transient state of the river system from a top view, which is incomplete. Therefore, a new approach is needed to take advantage of the available terrain information and provide channel characteristics for ungauged basins.

This paper evaluates a new method that estimates channel geometry properties and rating curves from high-resolution terrain data. This method uses hydrological terrain analysis to determine the Height Above Nearest Drainage (HAND) (Rodda, 2005; Renno et al., 2008), which is defined as the height of each grid cell with respect to the nearest stream cell it drains to. The HAND value of each grid cell thus indicates the water height 
at which that cell is inundated. The inundated extent corresponding to a given water level may be determined by selecting all the cells with a HAND value less than or equal to the given level. The water depth at each cell can then be computed using the water level minus its HAND value. The applicability of HAND to inundation mapping has been demonstrated in several studies (Rodda, 2005, Nobre et al., 2016). However, its application in describing river geometry information and retrieving stage-discharge relationships has not been explored. What hydraulic simulation really needs about river geometry is not the actual channel shape but the hydraulic parameters derived from the channel shape that are then used in the mass and momentum conservation equations. Hence, if the relationships between channel hydraulic parameters and stage height can be directly derived from hydrological terrain analysis products, as suggested by the results of the work here presented, inundation mapping can be performed with an alternative approach that does not rely on cross sectional information and hydraulic models (e.g. HEC-RAS).

This paper is organized as follows. Section 2 describes the workflow for the proposed approach: creation of HAND raster, evaluation of reach hydraulic properties and rating curves, and validation of the results. Section 3 presents a case study on the Blanco River (TX) and the comparison of the results with those obtained with a calibrated local HEC-RAS model. We also validate our approach on the Tar River (NC) against USGS gage observations and compare the resulting inundation extent against the FEMA 100-year flood plain. We discuss the results and remaining challenges in Section 4. Finally, concluding remarks are presented in Section 5.

\section{METHODS}

Our method consists of three parts. The first part is a hydrologic terrain analysis workflow, which is modified from the original HAND method (Renno et al., 2008), to compute the HAND raster for the NHDPlus river network. In the second part, using the calculated HAND raster, we derive hydraulic properties for all the reaches in the river network. In the third part, we take the derived hydraulic geometry and create a synthetic rating curve using Manning's equation for each reach. Following these steps, we compare the HAND-derived results to channel geometry and rating curves derived from local 
HEC-RAS models.

\section{Hydrologic Terrain Analysis}

The Height Above Nearest Drainage (HAND), first introduced by Rennó et al. (2008), is a special case of a hydrologic terrain proximity measure (Tesfa et al., 2011). There are multiple approaches to represent topography-driven flow over a terrain represented by a digital elevation model (DEM). The D8 model (O'Callaghan et al., 1984) assigns a single flow direction from each grid cell to one of its neighbors based on the steepest descent direction. It is the earliest and simplest method developed and is still widely used due to its simplicity and the convergence of the flows, which is desirable when mapping stream flow paths. The $D \infty$ model introduced by Tarboton (1997) generalizes $D 8$ by representing the flow direction as a vector along the direction of the steepest downward slope on one of the eight triangular facets centered at each grid cell. Flow from a grid cell is shared between the two downslope grid cells closest to the vector flow angle based on angle proportioning (Fig.1). Taking the advantage of the $D \infty$ flow model, Tesfa et al. (2011) developed methods to derive a wide range of flow related quantities useful to hydrological and environmental modeling, including the calculation of distance to stream (horizontal or vertical). The TauDEM software (Tarboton, 2016) implements these methods. Our method uses the $D \infty$ approach for the computation of HAND (vertical distance or drop to a stream, seeFig. 2) as implemented in the TauDEM software. 


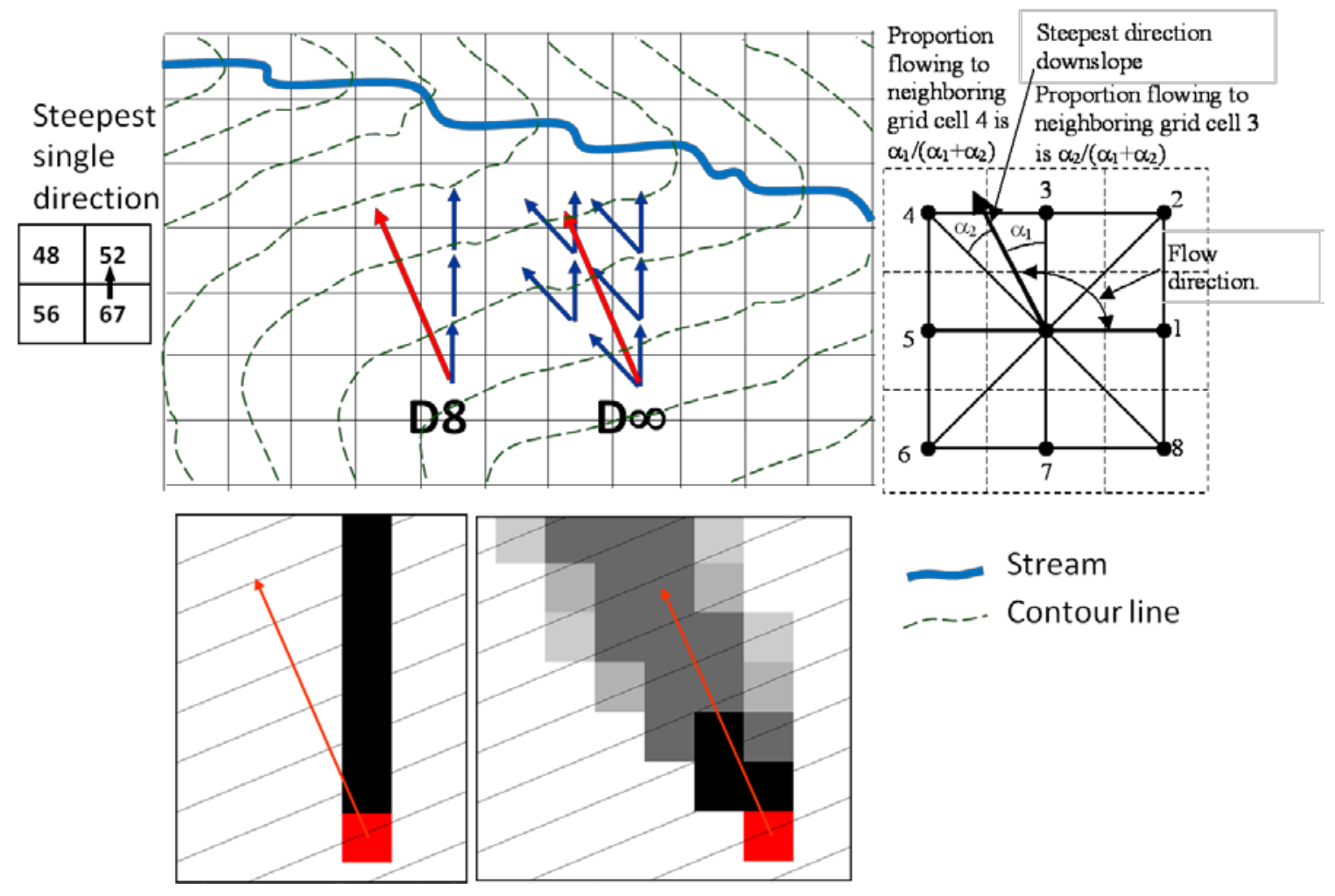

FIGURE 1: The $D 8$ and $D \infty$ flow models (figure reproduced from Tesfa et al., 2011).

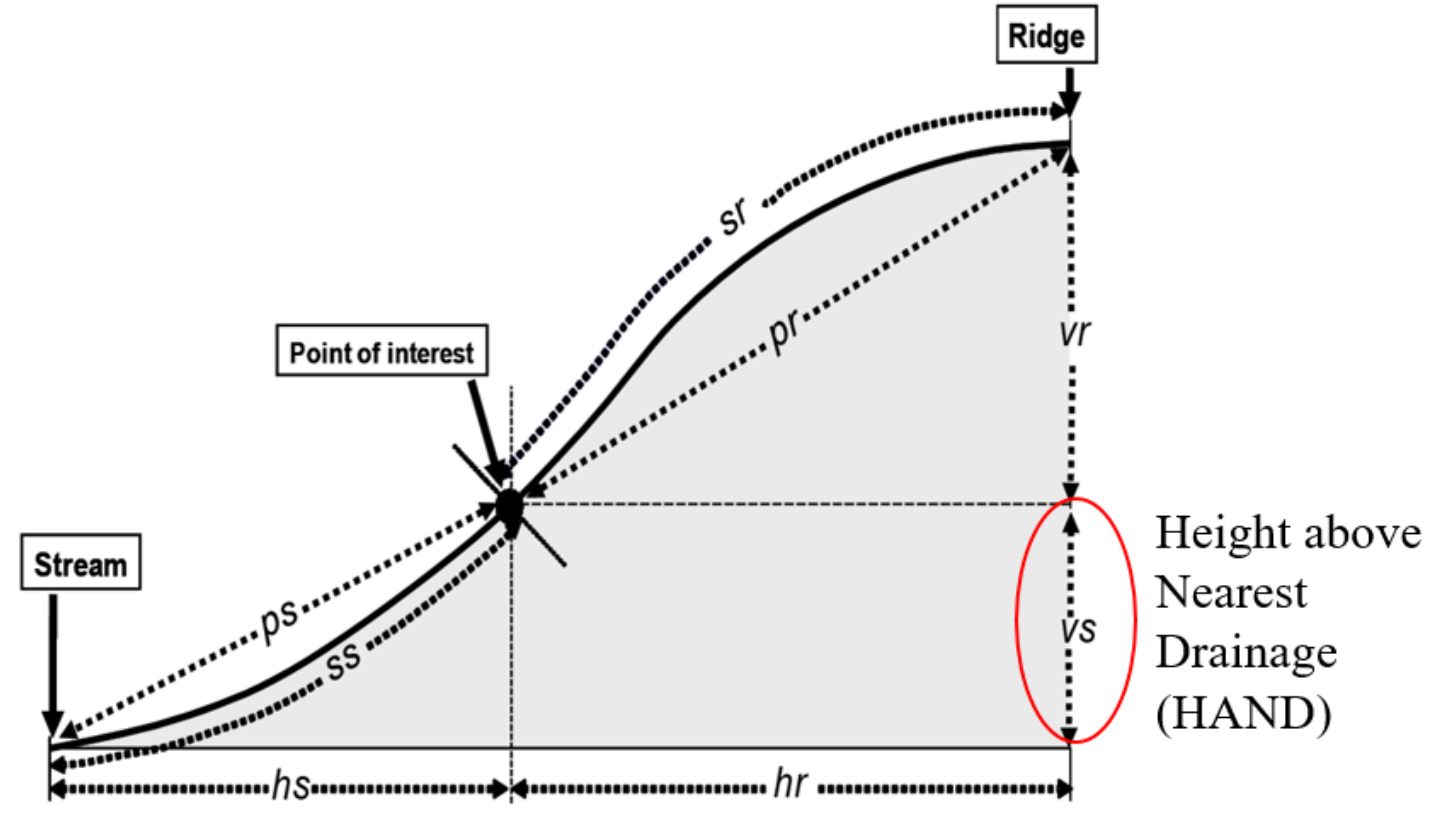

FIGURE 2: Definition of proximity measures for distances up (to ridge) and down to stream. HAND is evaluated using vs, the vertical drop to stream (figure reproduced from Tesfa et al. (2011)) 
The vertical drop to a stream (i.e., the HAND value) is computed as:

$$
h(i)=\frac{\left(\sum P_{i k}(\operatorname{drop}(i, k)+h(k))\right)}{\sum P_{i k}}
$$

where $P_{i k}$ is the proportion of grid cell $i$ that drains to grid cell $k, h$ is the vertical drop from a grid cell to the stream, and $\operatorname{drop}(i, k)$ the drop (change in elevation) from grid cell $i$ to $k$ defined as:

$$
\operatorname{drop}(i, k)=z(i)-z(k)
$$

where $z$ represents the elevation values at grid cells $i$ and $k$. In Equation (1) the sum is over the grid cells for which $P_{i k}$ is greater than 0 and for which $h(k)$ exists. The denominator in (1) is used to normalize for flow paths that leave the domain without reaching a designated end point grid cell (there is an option implemented in the code (Tarboton, 2016) to report no data rather than use this normalization). Tesfa et al. (2011) present this function as one option within a general distance to target set function where $\operatorname{drop}(i, k)$ may be replaced by a general distance measure computed in any number of ways (e.g. horizontally, vertically or along the slope). Note that drop to stream expressed in these equations is defined recursively with the drop from any grid cell as the weighted average of the drop from downslope cells, using cell to cell flow proportions as weights. The result is thus a form of weighted average along all the flow paths from a cell to the stream. The computation is initiated by setting the distances to 0 for all stream cells, and then enabling the evaluation of vs (i.e. HAND) for cells for which all downslope quantities in the domain have been evaluated. Grid cells where all downslope values are available are placed on a computational queue. To enable parallel computation, the domain is decomposed into portions, and a queue maintained for separate processes operating on each of them. Computational details are given in Tesfa et al. (2011).

The $D \infty$ approach with weighted average distance to the stream is used here as it provides a smoothing of the HAND values, effectively averaging sharp HAND differences between adjacent grid cells that may drain to stream cells of different elevation resulting from the $D 8$ approach. This approach appears to better represent the spreading out of water over the terrain when HAND is used to evaluate flood inundation and channel hydraulic properties. 
A prerequisite for evaluating HAND is a raster representation of the stream network. These are stream grid cells where HAND is assigned to be 0 . The TauDEM $D \infty$ distance down function may actually be evaluated for any target zone represented by a set of grid cells to which the distance is to be computed for whatever purpose. However, in the evaluation of HAND, the target zone is a raster representation of the stream network. There are many approaches to the definition of a raster stream network based on DEM flow models. These generally use the $D 8$ method, as defining divergent stream networks is impractical. TauDEM implements a number of methods (Tarboton and Ames, 2001; Tarboton et al., 1992; Tarboton et al., 1991), including simple contributing area threshold methods and more advanced methods based on measures of curvature to identify valley grid cells, objectively adapt to the complexity of the topography, and quantify drainage density.

In this paper, our interest is in stream networks aligned with the NHDPlus dataset used by the National Water Model. The NHDPlus stream network was mapped at a nominal 1:100,000 resolution. The USGS National Elevation Dataset (NED) DEM is currently available at $1 / 3$ arc sec $(\sim 10 \mathrm{~m})$ horizontal resolution across the continental US and represents information at a finer resolution more consistent with 1:24,000 scale mapping.

NHDPlus streams, however, do not always align with valleys in the $1 / 3$ arc sec NED DEM. To avoid the spurious HAND values that would result from calculating HAND to a direct rasterization of NHDPlus flowlines, we derived a stream raster at the same drainage density as the NHDPlus stream network, but aligned with 1/3 arc sec NED DEM. This operation was performed by identifying the upstream channel head of each first order NHDPlus stream and representing this as a grid cell with value of 1 , and setting all other grid cells to a value of 0 in a stream source weight grid. This weight grid was then used as input to a weighted flow accumulation calculation using D8 flow directions (TauDEM areaD8 function). Stream grid cells were mapped where the weighted flow accumulation was greater than 1 . The result is a raster representation of a stream network originating at each source point, but following down the valleys as indicated in the 1/3 arc sec DEM (Fig. 3). This stream raster was used as the target set in the evaluation of vertical distance using the TauDEM distance down function to obtain 
HAND values (Fig. 4).

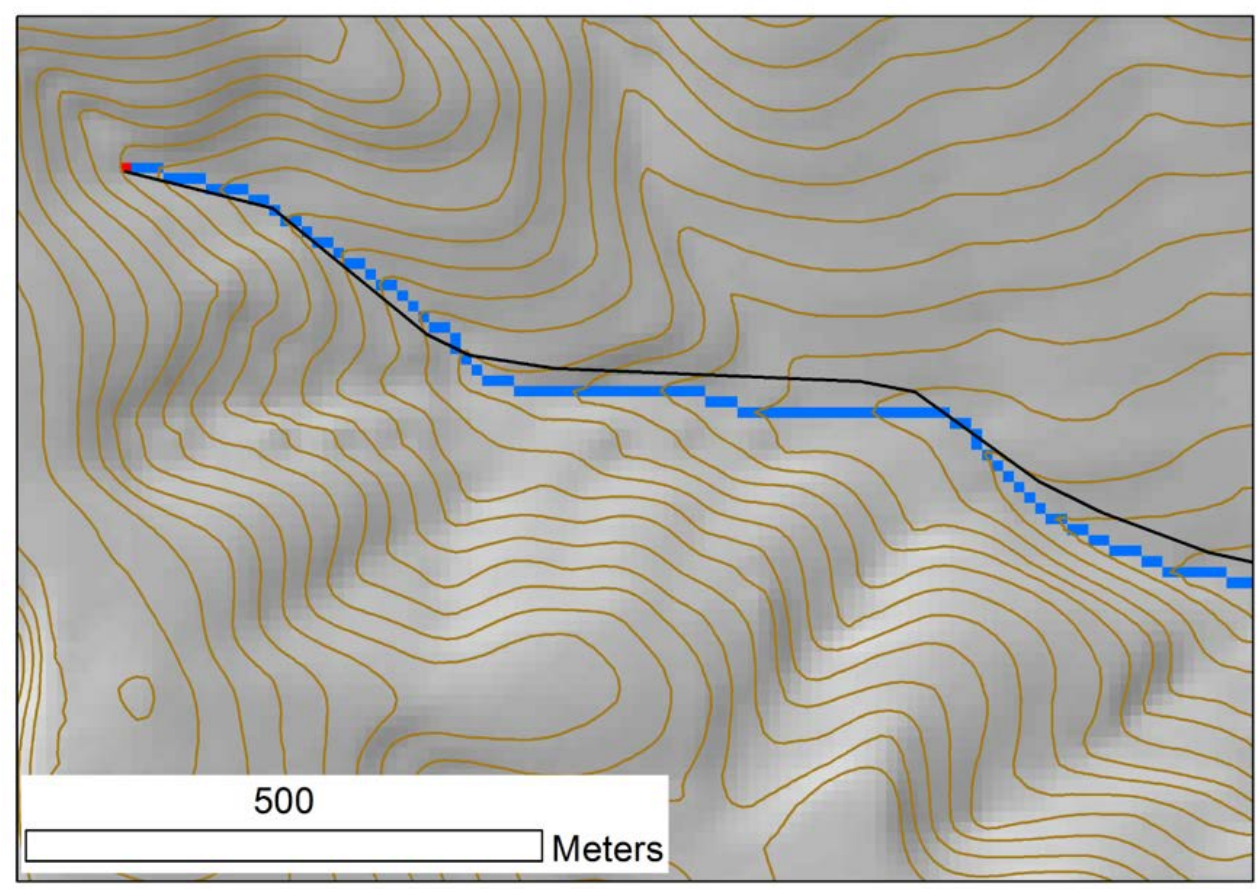

FIGURE 3: Stream raster derived from channel head sources of NHDPlus medium resolution streams. The red grid cell is the channel head source grid cell. Blue grid cells are the stream raster evaluated as a weighted flow accumulation of such red grid cells. The black line is NHDPlus stream. The lines are overlaid on elevation contoured at $2 \mathrm{~m}$ interval. The horizontal offset between the NHDPlus streams and the valleys as depicted by contours from the $1 / 3$ arc sec NED DEM is corrected in the stream raster. 


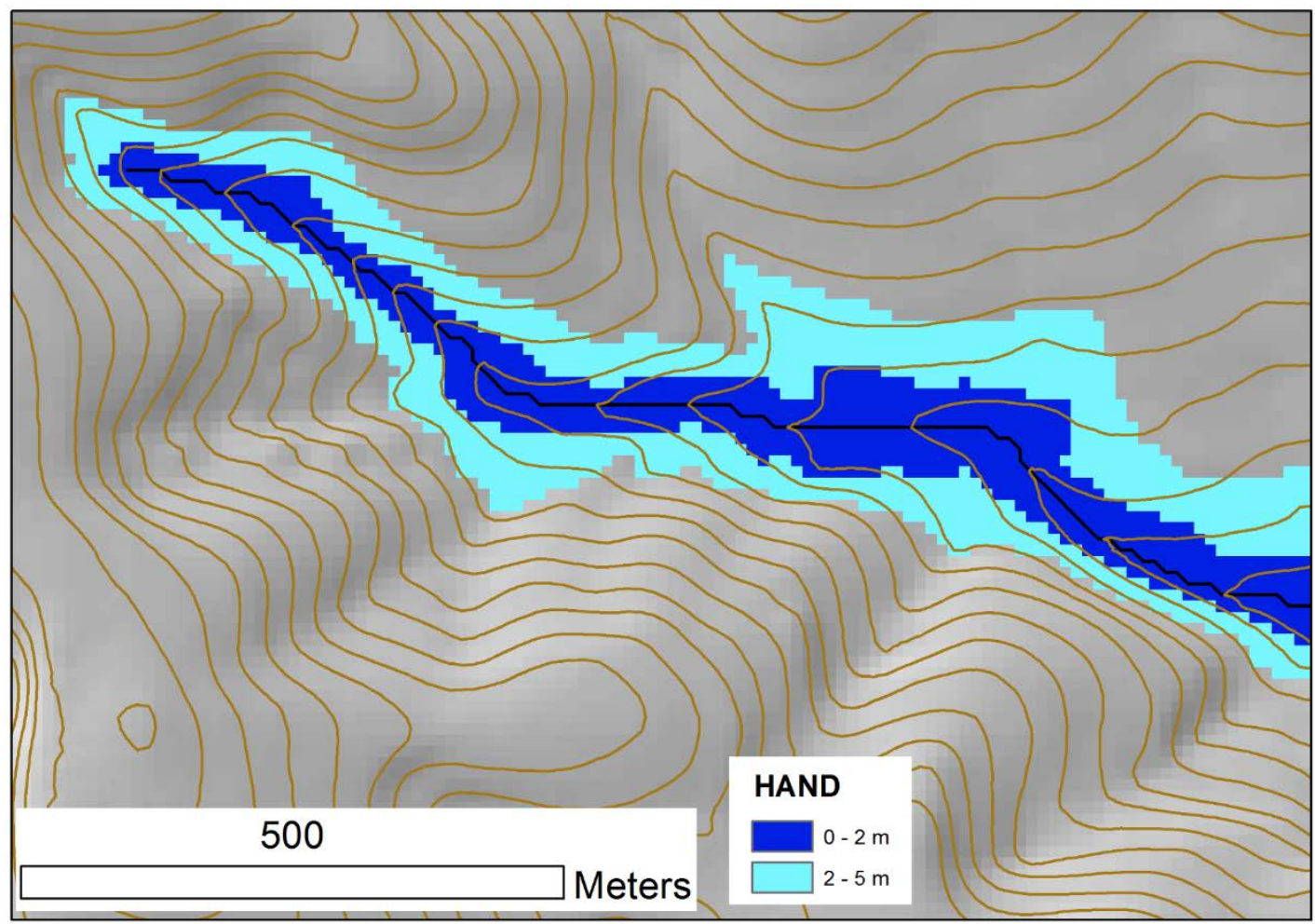

FIGURE 4: Height Above Nearest Drainage (HAND) evaluated on 1/3 arc sec NED DEM relative to a stream raster derived from NHDPlus medium resolution stream network source grid cells. $2 \mathrm{~m}$ terrain contour interval is drawn as background.

Implementation of the above methods requires a DEM that is hydrologically conditioned, or has had the pits removed so that each grid cell can drain to the edge of the domain, or to an identified internally draining sink along a flow path that is not increasing. In this work, the TauDEM pitremove function was used to hydrologically condition the DEM prior to the analysis.

The complete set of hydrologic terrain analysis processing steps is:

1. Fill pits using TauDEM pitremove function.

2. Calculate $D 8$ flow directions using TauDEM d8flowdir function.

3. Calculate $D \infty$ flow directions using TauDEM dinfflowdir function.

4. Define channel head source grid cells from NHDPlus streams.

5. Calculate the weighted flow accumulation using channel head grid cells as input to TauDEM D8 contributing area function. 
6. Define the stream raster using a threshold of 1 with weighted flow accumulation.

7. Calculate HAND using $D \infty$ distance to stream function with the vertical drop option.

\section{River Geometry and Rating Curve Estimation}

The conceptual basis for implementing HAND in inundation mapping is as follows. A river segment is defined as a stream reach $R$. The reach catchment, $C$, contributes the local drainage area of the stream reach $R$. Let us define $L$ as the length of the reach $R$ measured along its thalweg line. A measure location, $m$, along reach $R$ is defined by its percentage distance from the lower end of the reach, or in other words by the ratio of the length from that location to the lower end of the reach, divided by the length of the reach $L$. The water level, $y$, at any location $m$ along the stream channel is given by the difference between the water surface elevation and the minimum channel elevation at that location, designated by $y(m)$. The average water level along the stream reach is given by $y$. The HAND value, $h(s)$, is the elevation difference between a cell, $s$, on the land surface within the reach catchment and the minimum channel elevation at the location on the corresponding stream reach where water draining from that cell converges into the channel. The location, $s$, on the land surface is inundated if the water level in the channel reach is greater than the HAND value of that location, i.e. inundation occurs if $y>$ $h(s)$.

The conceptual basis for implementing HAND to estimate the channel hydraulic properties (Fig. 5) and rating curve is as follows: for reach $R$ at water level $y$, all the cells $s$ with a HAND value smaller than $y$ compose the inundated zone $F(y)$, which is a subarea

of the reach catchment $C$. The water depth at any cell $s$ in the inundated zone, $d(s)$, is the difference between the reach-average water level $y$ and the HAND of that cell $h(s)$, which can be represented as:

$$
d(s, y)=y-h(s), s \in F(y)
$$

Since a uniform reach-average water level $y$ is applied to check the inundation of any cell within the catchment, the inundated zone $F(y)$ refers to that reach level. 
The water surface area of the inundated zone at a water depth of $y, S(y)$, can be calculated as:

$$
S(y)=\sum_{s \in F(y)} A(s)
$$

where $A(s)$ is the area of cell $s$.

The channel bed area of the inundated zone at a water depth of $y, B(y)$, can be calculated as:

$$
B(y)=\sum_{s \in F(y)} A(s) \sqrt{\left(1+\operatorname{slp}(s)^{2}\right)}
$$

where $\operatorname{slp}(s)$ is the surface slope of cell $s$, expressed as rise over run or inverse tangent of the slope angle. This equation approximates the surface area of the grid cell as the area of the planar surface with surface slope, which intersects with the horizontal projected area of the grid cell.

The flood volume of the inundated zone $V(y)$ at a water depth of $y$ can be calculated as:

$$
V(y)=\sum_{s \in F(y)} A(s) d(s, y)
$$

If the reach length $L$ is known, the reach-average channel width at a water depth of $y$, $W(y)$, can be calculated as:

$$
W(y)=S(y) / L
$$

Similarly for the reach-average cross section area $A(y)$ :

$$
A(y)=V(y) / L
$$

and the reach-average cross section wetted perimeter $P(y)$ :

$$
P(y)=B(y) / L
$$

Combining the reach-average cross-sectional area $A(y)$ and the wetted perimeter $P(y)$ gives the reach-average cross section hydraulic radius $R(y)$ as:

$$
R(y)=A(y) / P(y)
$$

If the channel bed slope of reach $R$ is $S$ and a Manning's value is assumed as $n$, the Manning's equation can be applied to obtain a discharge $Q(y)$ corresponding to the water depth of $y$ at uniform flow as (in metric units): 


$$
\mathrm{Q}(y)=\left(\frac{1.00}{n}\right) A R^{\frac{2}{3}} S^{\frac{1}{2}}
$$

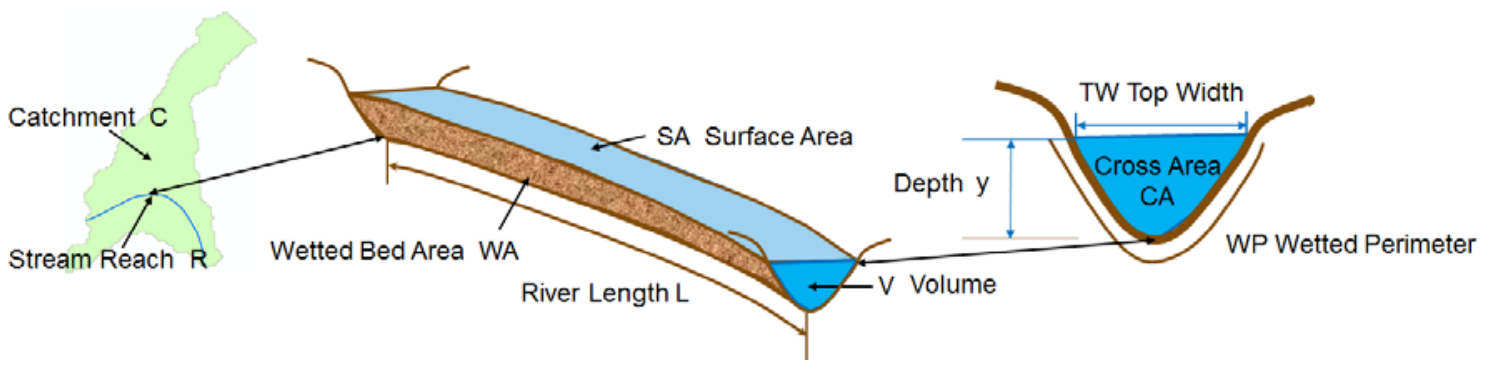

FIGURE 5: The conceptual model of HAND river geometry.

Computing the discharge $Q(y)$ for different water depths $y$ results in a synthetic rating curve for reach $R$. This rating curve relates the average water depth to the discharge in the reach $y(Q)$, where the discharge is assumed to be uniform along the reach. Therefore, this synthetic rating curve can be used as a tool to convert forecast discharges generated by large scale hydrologic models into corresponding water depths.

We implement this conceptual framework in the continental U.S with the 1/3 arc sec (10-meter) USGS 3DEP Elevation dataset and the NHDPlus dataset (Liu et al., 2018). The reach length and channel bed slope come from the attribute table of the flowline feature class in the NHDPlus dataset. By conducting these computational steps, a new continental-coverage high-resolution channel property dataset can be obtained for the continental U.S., indexed by the NHDPlus Common Identifier (ComId), and can be used to support future continental river dynamics research.

\section{Integrity Checking of River Geometry and Rating Curves}

The river channel geometries and synthetic rating curves defined using HAND are averages over the length of a channel reach derived by slicing the terrain surface longitudinally along the channel flow path, rather than transversely to the flow path, at intervals to form individual cross-sections, as is traditionally done in one dimensional river hydraulic models. One way of checking the integrity of the HAND-derived information is to compare the results with those derived from a HEC-RAS model of the same river. Therefore, we compare: (i) the minimum channel elevation, (ii) the stream geometry, and (iii) the synthetic rating curve. 
The minimum channel elevation at a particular measure location $m, z_{c}(m)$, is the elevation above geodetic datum of the stream thalweg at that location. When a stream is represented by a sequence of cells in a DEM, the DEM cell that corresponds to location $m_{i}$ has a DEM channel elevation above geodetic datum of $z_{d}(m)$. Because digital elevation models are smoothed versions of land surface topography, and because the digital elevation model may have been created when the channel was partly filled with water, the DEM channel elevation is generally higher than the minimum channel elevation. The value $\Delta z(m)=z_{d}(m)-z_{c}(m)$ represents the bed elevation difference between the DEM channel elevation and the thalweg channel elevation at that location. The mean value of this bed elevation difference along a stream reach is given by $\Delta z$.

An assumption of our implementation that needs to be evaluated is whether a DEM at a resolution of 10 meters is able to capture the terrain details within the channel. One way of carrying out this evaluation is to compare the streamline bed elevation profile extracted from the 10m DEM with the minimum channel elevation in a HEC-RAS model obtained by connecting the minimum elevation of HEC-RAS cross sections from upstream to downstream. In order to keep the same profile length and elevation sampling rate in the two methods, we adopt the streamline measure system of the HEC-RAS model, and obtain the DEM-derived profile by intersecting the DEM-derived flowline with the HEC-RAS cross sections and extracting the DEM elevations of the intersected locations.

Because $\Delta z$ is generally greater than zero, it is useful to introduce a bottom shift into the HAND-derived water levels reflecting the "shelf effect" where the bottom of a DEM channel is actually flat over a finite area. Using this approach, the channel width $W$ is a positive number when the water level $y$ is zero, so the true water depth is larger than that computed using the DEM alone.

HAND-derived channel hydraulic properties can also be compared with those derived from river geometry information stored in HEC-RAS models. The main channel property that we evaluated is the channel width, because it is a description of the river geometry that is readily obtained by the HAND method. To do this, we derive a water level-channel width relationship from the HAND raster for a river segment using Eq. (7). Since the cross section shape is stored in HEC-RAS, a similar relationship can be established from the shape of each cross section located on the study reach. These cross 
section level-width relationships form a sample space for a given stream reach. If the HAND-derived relationship falls within this sample space, we have some confidence that the accuracy of the HAND-derived river geometry information is comparable to that of the river geometry data used in local hydraulic simulations. Taking the channel widths for all the cross sections on the segment at the same water level, together with the distance between adjacent cross sections, we can compute the flood volume corresponding to the given water depth. If the volume is divided by the total length of the segment, an equivalent reach-averaged channel width can be derived from these cross sectional shapes. Repeating this process for a series of threshold water depths gives us a reachaveraged water level-width relationship derived from cross sectional shapes. Calculating the difference between this cross section-derived relationship and the HAND-derived relationship also helps to evaluate the quality of HAND-derived river geometry information.

Finally, HAND-derived rating curves are compared with the rating curves stored in local HEC-RAS models. If a HEC-RAS project contains the simulation at multiple flow conditions, a rating curve will be generated for each cross section from the steady flow simulation results. Similar to the channel width sample space we use to validate river geometry, a rating curve sample space for the river segment is established from rating curves from different cross sections. To better quantify the water depth uncertainty brought by channel geometry, a fixed flow rate is assigned to every cross section in a HEC-RAS model for a given channel reach to create a representative flow condition that is replicated with the HAND-derived rating curve. In this way, the water depth uncertainty caused by the difference in discharge between HAND and HEC-RAS is eliminated. This median rating curve in the rating curve sample space from HEC-RAS is chosen as the reference to validate the HAND-derived rating curves. The optimal roughness value is selected for the HAND-derived rating curve by minimizing the rootmean-square error (RMSE) between the HAND-derived rating curve and the median rating curve from HEC-RAS. 


\section{APPLICATIONS}

\section{Study Area and Data}

In order to evaluate our approach, we conduct a case study on the Blanco River (Fig. 6) following the steps described in the Methods section. The Blanco River is located in Central Texas, which is one of the most flash-flood prone regions in North America. In May 2015, a historic flash flood occurred across parts of Central Texas causing severe life and property losses. The Blanco River was one of the most affected areas in this flood due to a flood wave of more than 12 meters in water depth.

The network of the Blanco River watershed is composed of 170 mediumresolution NHDPlus reaches. The total drainage area is about $1,100 \mathrm{~km}^{2}$, and the average drainage area of the individual reach catchments is $6.7 \mathrm{~km}^{2}$. The total river length is about $540 \mathrm{~km}$, and the average river length of the reaches is $3.2 \mathrm{~km}$. For the hydrological terrain analysis portion, we created the HAND raster for the Blanco River watershed. The DEM used in this study is the 1/3 arc-second DEM from the USGS 3DEP Elevation dataset with horizontal resolution of about 10 meters. The RMSE is 1.5 meters and represents the vertical accuracy of the DEM (Gesch et al., 2014). A calibrated HEC-RAS steady flow model, covering the lower half of the Blanco River main channel, was provided by the Fort Worth District of the U.S. Army Corps of Engineers and used as the reference for river geometry and rating curve comparison. In particular, we implemented the approach for a single NHDPlus reach with COMID 1630223. We chose this reach because: (1) its length is close to the average river length of the entire NHDPlus network with 2.67 million reaches, making it a representative reach for the catchment; (2) the reach is covered by the local HEC-RAS model and there are 8 cross sections lying on this reach; and (3) the reach is close to Wimberley where 11 people were killed in the 2015 Memorial Day Flood, adding practical significance to understanding this reach. 


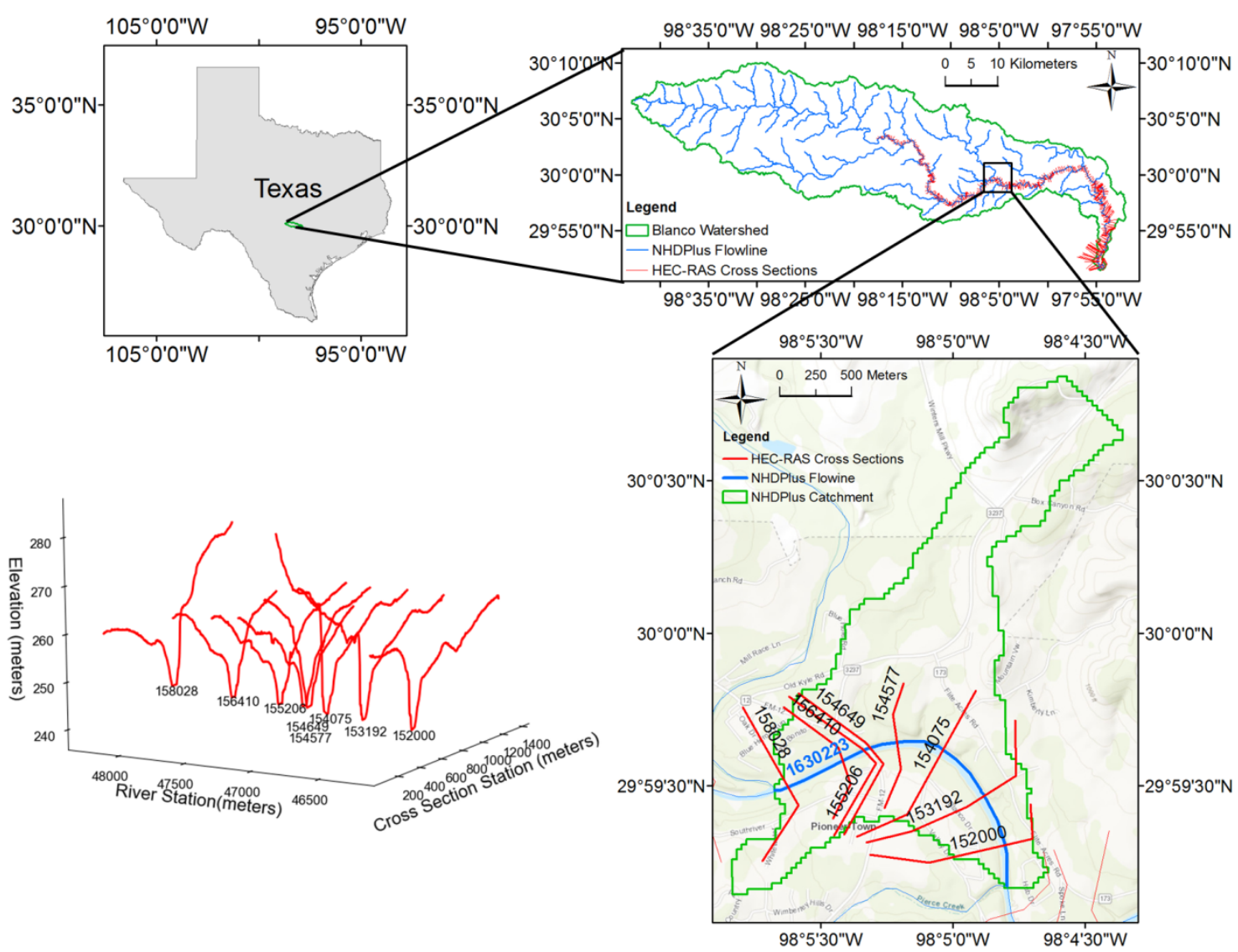

FIGURE 6: The Blanco River watershed, NHDPlus reach 1630223, and the geometry of HEC-RAS cross sections located on the reach.

The eight HEC-RAS cross sections are also shown in Figure 6. The main channel Manning's $n$ value is 0.045 for all the cross sections, while the floodplain Manning's $n$ varies from 0.06 to 0.1 . The Manning's $n$ values applied in the HEC-RAS model provide a proper range for roughness adoption when the depth-discharge relationship (rating curve) is established through HAND.

\section{Hydrologic Terrain Analysis}

A 10-meter HAND raster (Figure 7) was generated for the Blanco River watershed based on the 10 -m resolution DEM raster and the 10-meter river network raster initiated at NHDPlus stream sources. While the original DEM has elevations that range from 165 meters to 618 meters, a difference of 453 meters, the HAND raster ranges from 0 to 161 meters. This difference in elevation range shows that HAND measures 
only the relief relative to streams.

In addition, since the HAND raster is built upon flow directions, derived from a hydrologically conditioned DEM, it forms a continuous surface across the whole domain. This continuity brings two advantages to the HAND method over the planar linear interpolation approach used for inundation mapping based on cross sections (Apel et al., 2009): (1) local depressions that are never connected to the flow can be avoided; and (2) the mass conservation law holds.

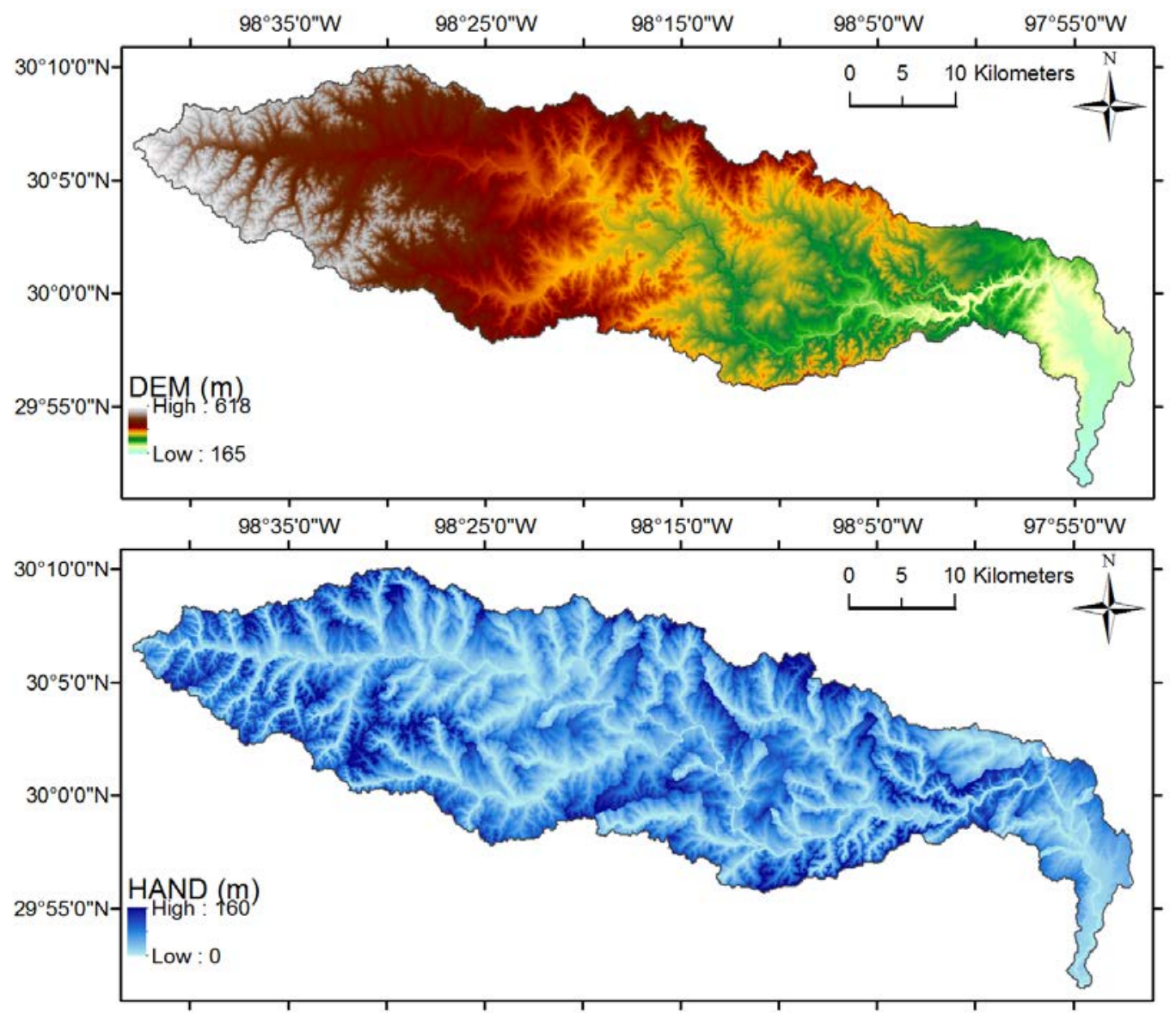

FIGURE 7: DEM and HAND for the Blanco River watershed.

Figure 8 illustrates the stream network and NHDPlus channel heads used to define the stream network raster for the Blanco River watershed. The blue polylines are from the NHDPlus flowline feature class. A geoprocessing tool was used to identify the channel heads of all the first-order reaches. The cells on the flow paths starting from these channel heads following the $D 8$ flow directions were identified as stream cells. Although the majority of the DEM-derived flowlines line up with the NHDPlus flowline features, 
the advantage of adopting DEM-derived flowlines instead of NHDPlus flowlines is that it guarantees that the streams pass through the valley portion of the digital terrain dataset.

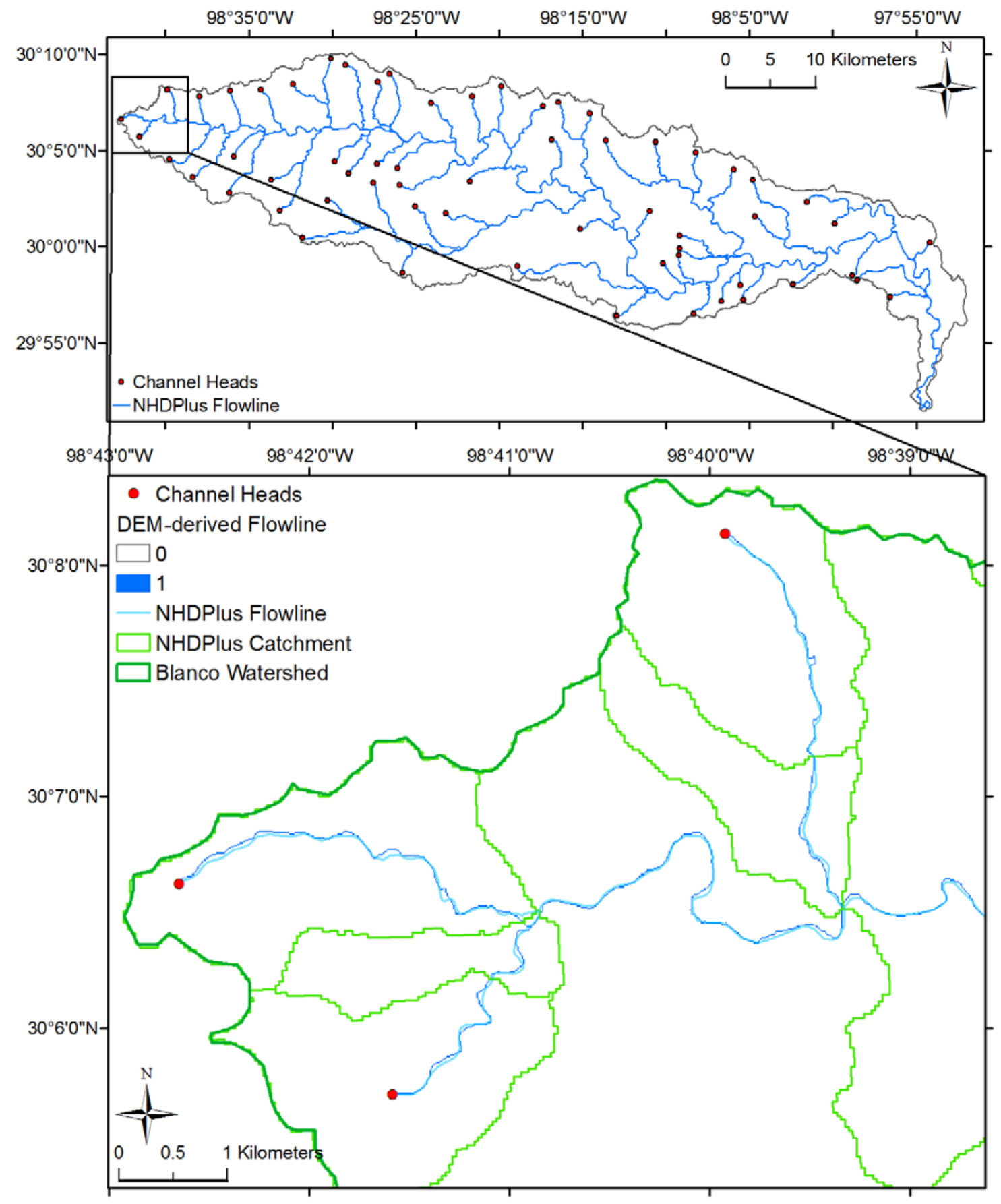

FIGURE 8: Stream definition in HAND. 


\section{River Geometry and Rating Curve Estimation}

By setting a water level threshold to the HAND raster, the inundation extent consisting of all the cells with a HAND value smaller than the threshold can be generated. The water depth raster is then computed by using the threshold water level value subtracted from the HAND value (Eq. (3)). All the inundated cells have a positive water depth and the stream cells have a water depth equal to the threshold water level.

The procedure for obtaining river geometry properties for each reach is illustrated here for the selected study reach and catchment (COMID: 1630223). We first clip the Blanco River watershed HAND raster with the catchment boundary polygon to obtain a HAND subset for that catchment. From the HAND raster, we create the water depth grids that correspond to a series of threshold water levels from 0 to 18.3 meters (60 feet) at an interval of 0.3 meters (1 foot). As shown in Figure 9, water spreads out of the channel and the depth at the same location increases as the water level rises up. Following the method described earlier, we get the water level-channel geometric property relationships for this reach as shown in Table 1.

To estimate the rating curve for that reach, the derived water level-cross sectional area and water level-hydraulic radius relationships, together with the river length and reach average slope attributes of that specific reach from the NHDPlus dataset and Manning's roughness coefficient, are substituted into the Manning's flow resistance equation. In this study for reach 1630223, the segment length is 2.1 kilometers, and the channel bed slope is 0.00198. Manning's $n$ value was taken as 0.05 for consistency with the HEC-RAS model for this river. Selection of Manning's $n$ is a source of uncertainty in this approach and its calibration is discussed in the validation section. 

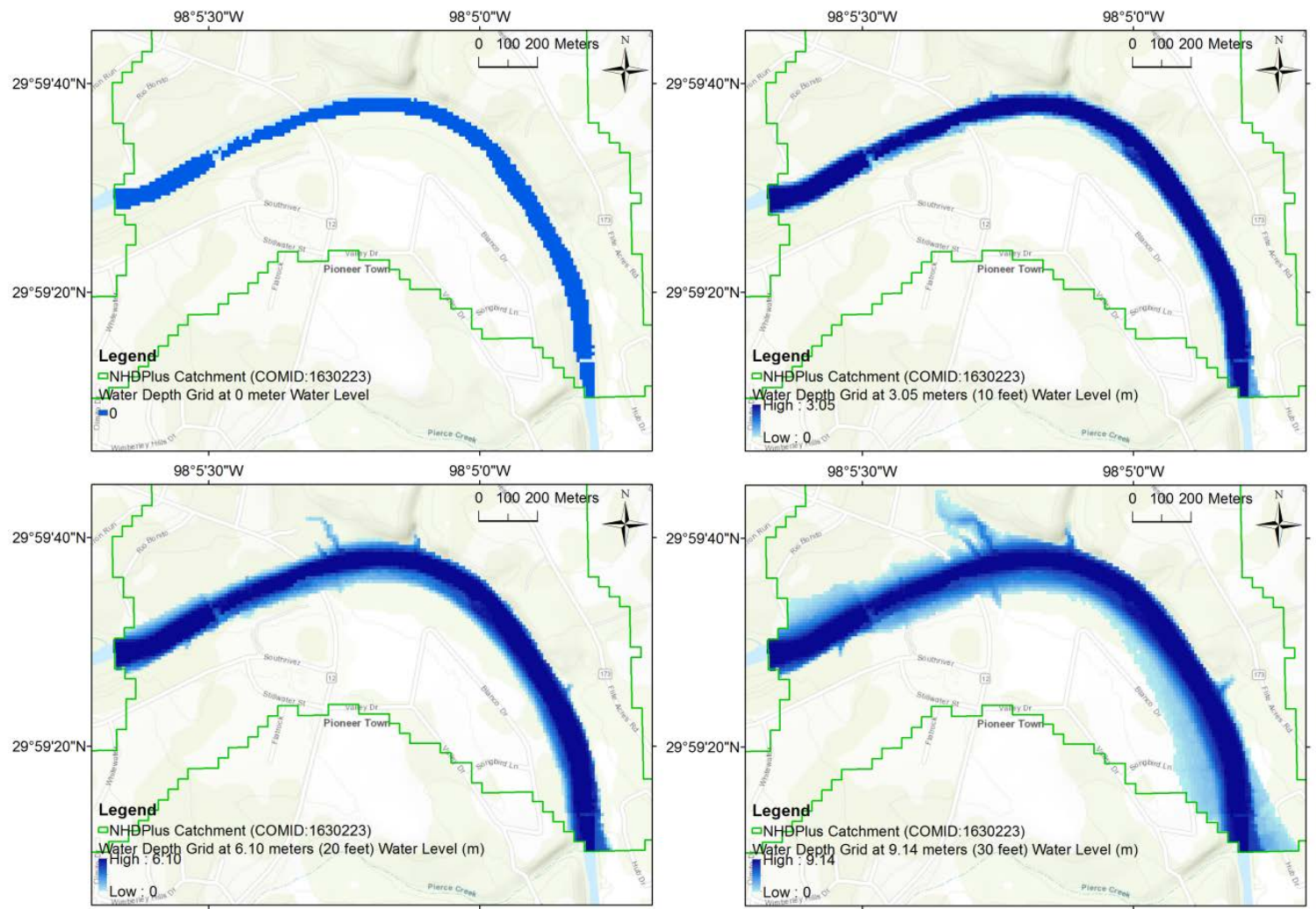

FIGURE 9: Water depth grids at different water levels (0, 3.05, 6.10, and 9.14 meters, respectively).

Table 1: HAND-derived river geometry parameters and rating curve for reach 1630223.

\begin{tabular}{cccccccccc}
\hline $\begin{array}{c}\text { Water } \\
\text { Level } \\
(\mathrm{m})\end{array}$ & $\begin{array}{c}\text { Number } \\
\text { of } \\
\text { Inundate } \\
\mathrm{d} \text { Cells }\end{array}$ & $\begin{array}{c}\text { Water } \\
\text { Surface } \\
\text { Area } \\
\left(10^{4} \mathrm{~m}^{2}\right)\end{array}$ & $\begin{array}{c}\text { Channel } \\
\text { Bed Area } \\
\left(10^{4} \mathrm{~m}^{2}\right)\end{array}$ & $\begin{array}{c}\text { Flood } \\
\text { Volume } \\
\left(10^{4} \mathrm{~m}^{3}\right)\end{array}$ & $\begin{array}{c}\text { Channel } \\
\text { Width } \\
(\mathrm{m})\end{array}$ & $\begin{array}{c}\text { Wetted } \\
\text { Perimeter } \\
(\mathrm{m})\end{array}$ & $\begin{array}{c}\text { Wet } \\
\text { Area } \\
(\mathrm{m} 2)\end{array}$ & $\begin{array}{c}\text { Hydraulic } \\
\text { Radius } \\
(\mathrm{m})\end{array}$ & $\begin{array}{c}\text { Discharge } \\
\left(\mathrm{m}^{3} / \mathrm{s}\right)\end{array}$ \\
\hline 0 & 858 & 8 & 8 & 0 & 38 & 38 & 0 & 0 & 0 \\
3.048 & 1735 & 16 & 16 & 37 & 77 & 78 & 181 & 2.32 & 282 \\
6.096 & 2399 & 22 & 22 & 95 & 107 & 108 & 463 & 4.29 & 1085 \\
9.144 & 3646 & 33 & 34 & 176 & 163 & 164 & 856 & 5.21 & 2286 \\
12.192 & 6045 & 55 & 56 & 312 & 270 & 272 & 1516 & 5.57 & 4236 \\
15.240 & 8360 & 77 & 77 & 514 & 373 & 377 & 2501 & 6.64 & 7856 \\
18.288 & 10944 & 100 & 101 & 781 & 488 & 493 & 3801 & 7.71 & 13190 \\
21.336 & 13436 & 123 & 124 & 1124 & 600 & 605 & 5467 & 9.04 & 21093 \\
24.384 & 15927 & 146 & 147 & 1534 & 711 & 716 & 7467 & 10.43 & 31682 \\
\hline
\end{tabular}

Theoretically, when the water level is equal to zero, the channel is represented by a thalweg line with a width of zero. However, from Figure 9(a) and the zero depth row in Table 1, we can see that there is a bottom width of 38 meters in the HAND-derived river geometry, meaning that the HAND-derived river geometry is not able to reach down to 
the level of the thalweg. Therefore, a shift must be made to the bottom of the HANDderived river geometry information.

\section{River Geometry and Rating Curve Validation with HEC-RAS}

To evaluate the 10-meter terrain dataset used to estimate river geometry, a streamline profile comparison was conducted for the whole modelled river segment and the single reach 1630223. For the profile comparison of reach 1630223 (shown in Figure 10(a)), the DEM-derived profile is 0.13 meters higher than the HEC-RAS profile on average with a standard deviation of 0.12 meters. The profile derived from the pitremoved DEM, which is the actual one used in HAND computation, is 0.88 meters higher than the HEC-RAS profile on average, with a standard deviation of 0.95 meters. The results show that for this reach, the 10-meter DEM is very close to the thalweg, but the pit filling process introduces extra bias to the accuracy of the terrain dataset, and affects the accuracy of HAND results. The same comparison is repeated for the entire profile across the modelled channel shown as Figure 10(b) and the same conclusion can be drawn. For the entire 82-kilometer modelled segment, the DEM-derived profile is 0.49 meters higher than the HEC-RAS profile on average with a standard deviation of 1.23 meters; the profile derived from the pit-removed DEM is 0.99 meters higher than the HEC-RAS profile on average with a standard deviation of 1.26 meters.

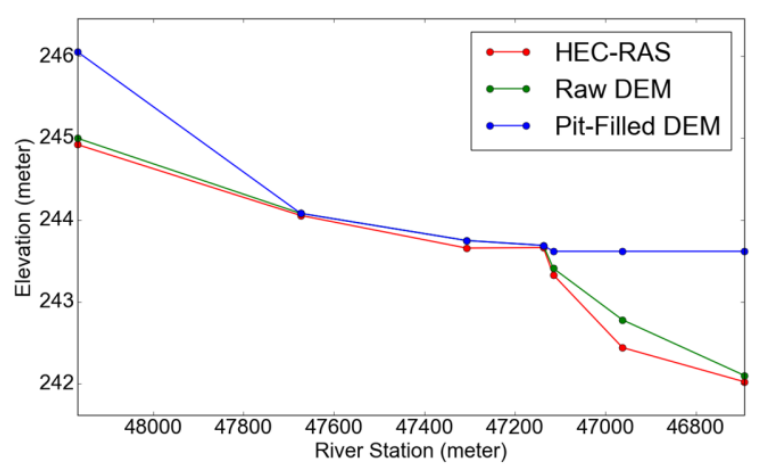

(a) Reach 1630223

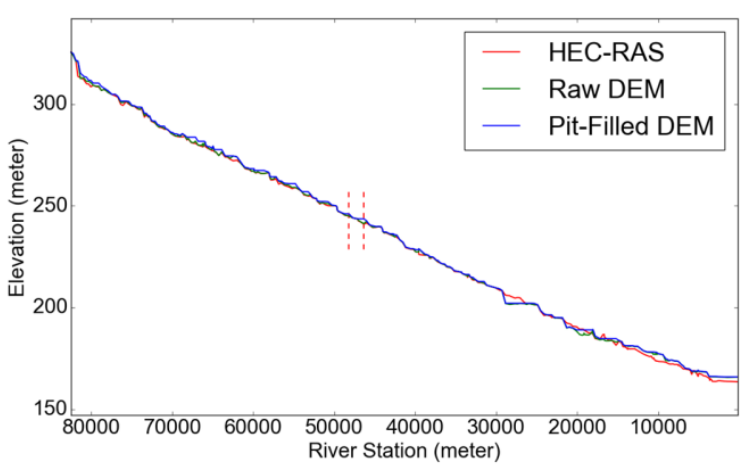

(b) Entire Modelled River Segment

FIGURE 10: Comparison between the minimum channel elevation profiles from the DEM, the pit-filled DEM, and HEC-RAS streamline profile comparison.

To validate the HAND-derived river geometry, we computed a water levelchannel width relationship for each cross section and a reach-average relationship, 
depending on cross sectional shapes and distances. These relationships compose the validation reference (shown by the dotted red line in Figure 11) derived from the HECRAS model. According to Table 1, when the water depth is zero, a corresponding channel width of 38-meter is derived from the HAND raster for reach 1630223. From Figure 11, a depth of 0.64 meters is interpolated on the reach-average water level-width relationship for a 38-meter channel width. This depth is treated as the bottom shift needed to adjust HAND-derived river geometry in this reach due to the limitation caused by the terrain dataset resolution. After the adjustment is made, the comparison between HAND-derived depth-width relationship and HEC-RAS-derived depth-width relationship is shown as Figure 11. As we can see, the HAND-derived depth-width relationship always falls in the sample space composed of individual cross section depth-width relationships. The RASderived reach-average channel width is 12.04 meters wider than the HAND-derived reach average width on is within the depth range from 0.92 meters ( 3 feet) to 15.24 meters (50 feet). The standard deviation of the width difference is 19.33 meters. If the difference is normalized with the RAS-derived reach-average channel width in that range, the relative mean difference is 3.2 percent, which demonstrates a good fit of the HAND-derived river geometry to the actual channel hydraulic condition. 


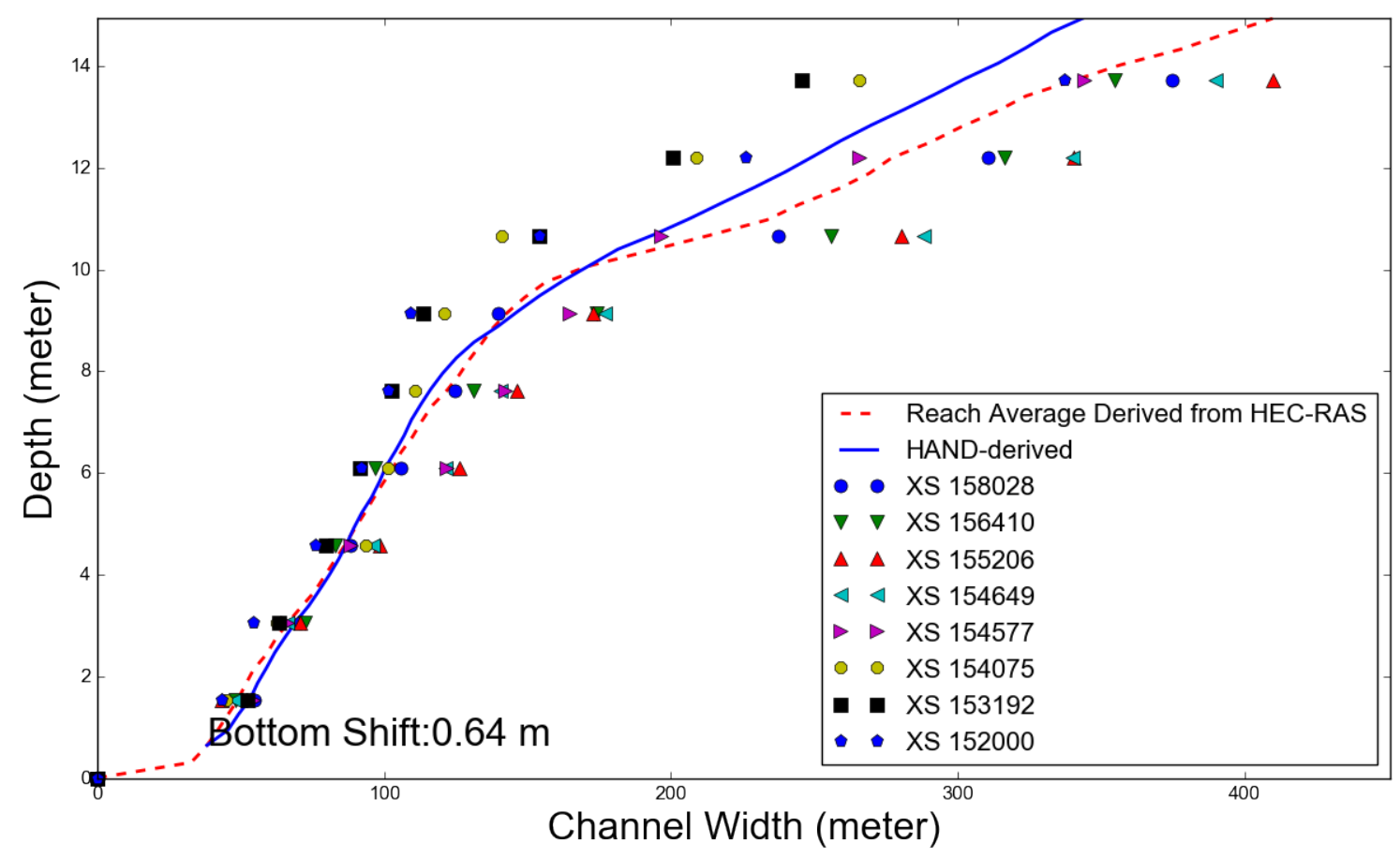

FIGURE 11: Comparison between HAND-derived and RAS-derived depth-width relationships on reach 1630223 (“XS" stands for "Cross Section". The distribution and geometry of cross sections can be found in Figure 6).

To validate the rating curves derived with HAND, we conducted steady flow simulation with HEC-RAS under multiple flow conditions. In each cross section, the water level-discharge data pair under a single flow condition is a point on the rating curve of that cross section and the rating curves of all the cross sections in a reach compose the reference rating curve sample space. There are eight flow conditions (profiles) stored in the approved HEC-RAS model, which correspond to the 2-yr (232 $\left.\mathrm{m}^{3} / \mathrm{s}\right), 5-\mathrm{yr}\left(736 \mathrm{~m}^{3} / \mathrm{s}\right)$, 10-yr (1249 m³ $/ \mathrm{s}), 25-y r\left(2067 \mathrm{~m}^{3} / \mathrm{s}\right), 50$-yr $\left(2784 \mathrm{~m}^{3} / \mathrm{s}\right), 100$-yr (3568 m³ $\left./ \mathrm{s}\right), 250$-yr $\left(4701 \mathrm{~m}^{3} / \mathrm{s}\right)$, and $500-\mathrm{yr}\left(5607 \mathrm{~m}^{3} / \mathrm{s}\right)$ floods in the Blanco River. To better represent the depth-discharge relationship in low flow condition, we added six extra profiles. One of these profiles is the annual mean flow condition $\left(2 \mathrm{~m}^{3} / \mathrm{s}\right)$, which is stored as an attribute of every reach in the NHDPlus flowline attribute table. The other three profiles correspond to $20 \%\left(0.4 \mathrm{~m}^{3} / \mathrm{s}\right), 50 \%\left(1 \mathrm{~m}^{3} / \mathrm{s}\right)$ and $80 \%\left(1.6 \mathrm{~m}^{3} / \mathrm{s}\right)$ mean annual flow. The last two profiles $\left(79 \mathrm{~m}^{3} / \mathrm{s}\right.$ and $155 \mathrm{~m}^{3} / \mathrm{s}$ ) are obtained by linearly interpolating between the annual mean flow and the 2-yr flood. The downstream boundary condition of the steady flow simulation is set as the normal depth. Since we set a constant flow rate to all the 
cross sections across the reach, for each flow condition, a box plot can be used to quantify the variability in stage across the cross sections due to shape differences and other hydraulic interactions. Connecting the median stage of each box plot produces a median rating curve. This median rating curve is applied to identify the corresponding discharge for the channel bottom missing in the HAND-derived river geometry and rating curve. For the depth shift of $0.64 \mathrm{~m}$, the discharge added to the bottom of the HANDderived rating curve is $22 \mathrm{~m}^{3} / \mathrm{s}$. Then the entire HAND-derived rating curve is shifted with a depth of $0.64 \mathrm{~m}$ and a discharge of $22 \mathrm{~m}^{3} / \mathrm{s}$. Figure 12 shows the comparison between the HAND-derived rating curve (after shift) and the HEC-RAS rating curve sample space. The Manning's $n$ roughness value used to build this rating curve is 0.05 . Flow conditions larger than the minimum discharge in HAND-rating curve are used to quantify the fitness of HAND-derived rating curve and the reference median rating curve. Therefore, 10 of these 14 flow conditions are adopted. For those specific flow rates, corresponding stage heights are obtained from the HAND-derived rating curve and the HEC-RAS median rating curve. For the case with the Manning's $n$ of 0.05, the water level read from the HAND-derived rating curve is 0.52 meters higher than the stage height read from the HEC-RAS median rating curve on average with a standard deviation of 0.09. If the difference is normalized using the median stage height, it represents a mean difference of 7.7 percent. 


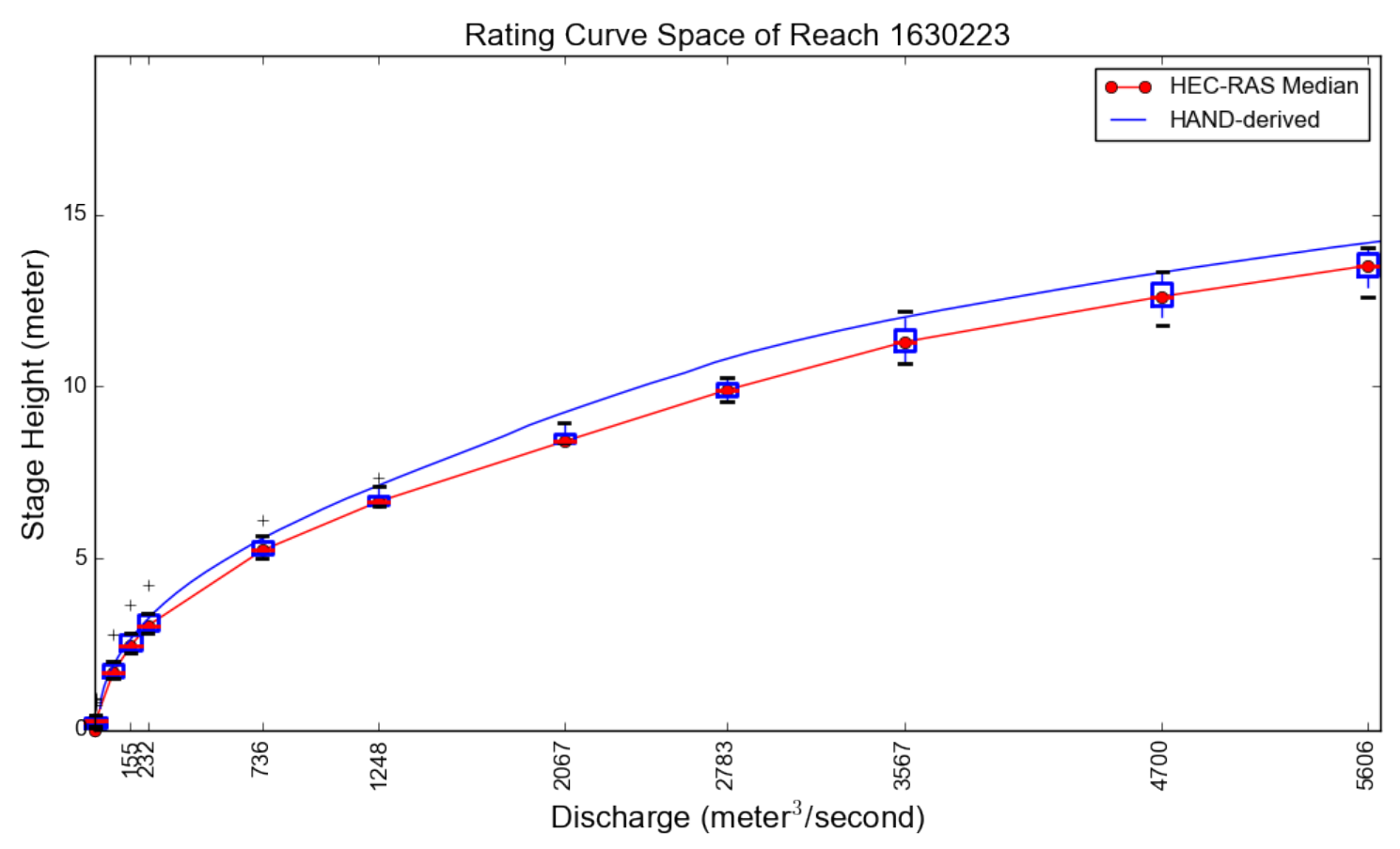

FIGURE 12: Comparison between HAND-derived and RAS-derived rating curves on reach $1630223(n=0.05)$.

The optimal roughness value is determined by minimizing the mean stage height difference in absolute value for the given flow conditions searching across Manning's $n$ values between 0.040 and 0.06 at an interval of 0.001 . The variation of the mean stage height difference within this range is shown in Figure 13. The mean stage height difference absolute value is minimized to 0.02 meters at a Manning's $n$ of 0.043 , which is slightly smaller than the channel roughness value used in the HEC-RAS model (0.045). This difference is inconsequential. If the actual 0.045 Manning's $n$ value is adopted, the mean difference is 0.17 meters, which is an acceptable conversion for inundation mapping purposes. The rating curve comparison with the Manning's $n$ of 0.045 is shown in Figure 14. The fact that the calibrated and HEC-RAS $n$ values are close and the rating curves consistent, supports the finding that the HAND DEM analysis is a valid approach to determine hydraulic parameters and is expected to produce results comparable to the more data intensive HEC-RAS approach, which is difficult to apply at continental scale. 


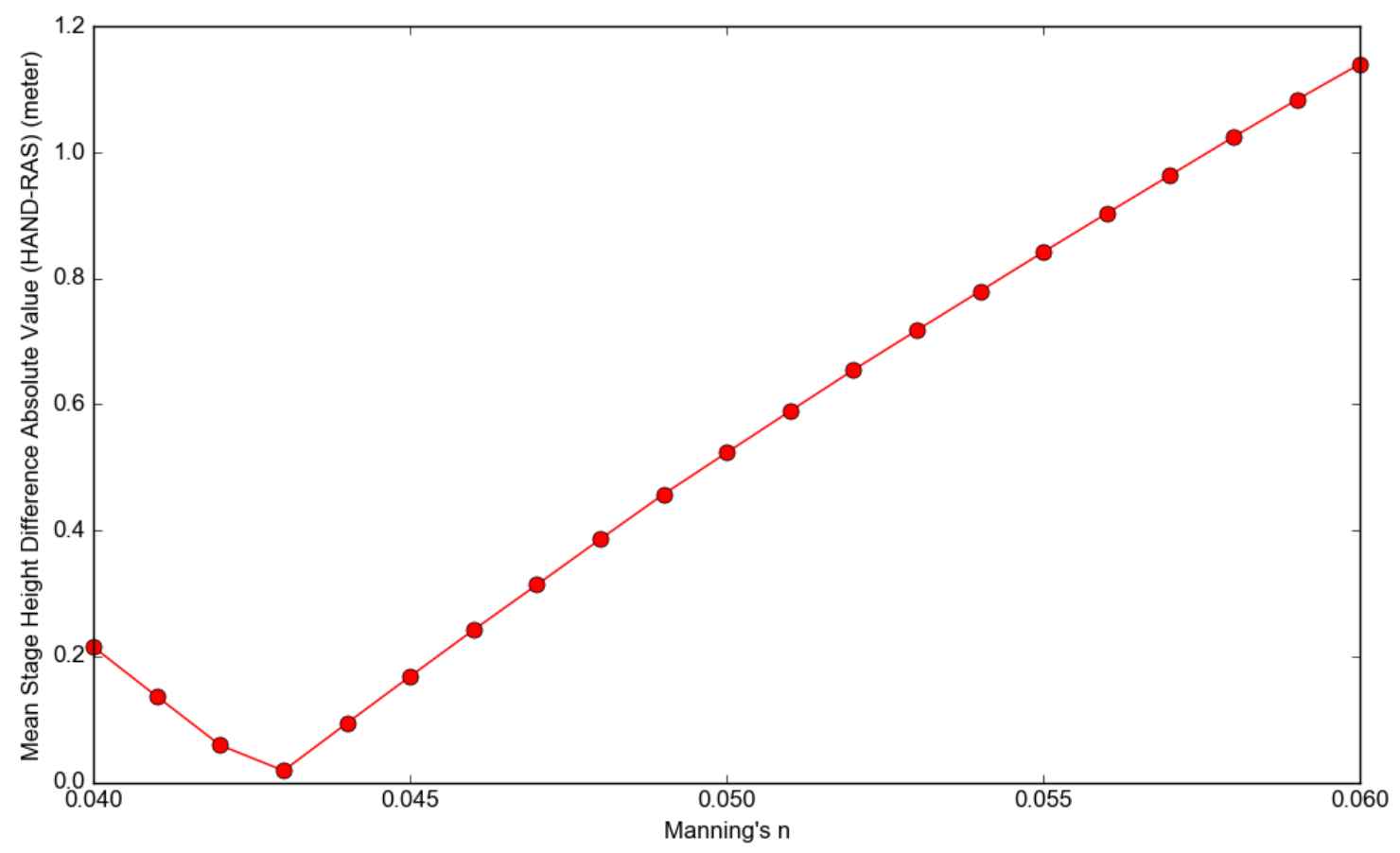

FIGURE 13: Relationship between Manning's $n$ and the mean stage height difference absolute value.

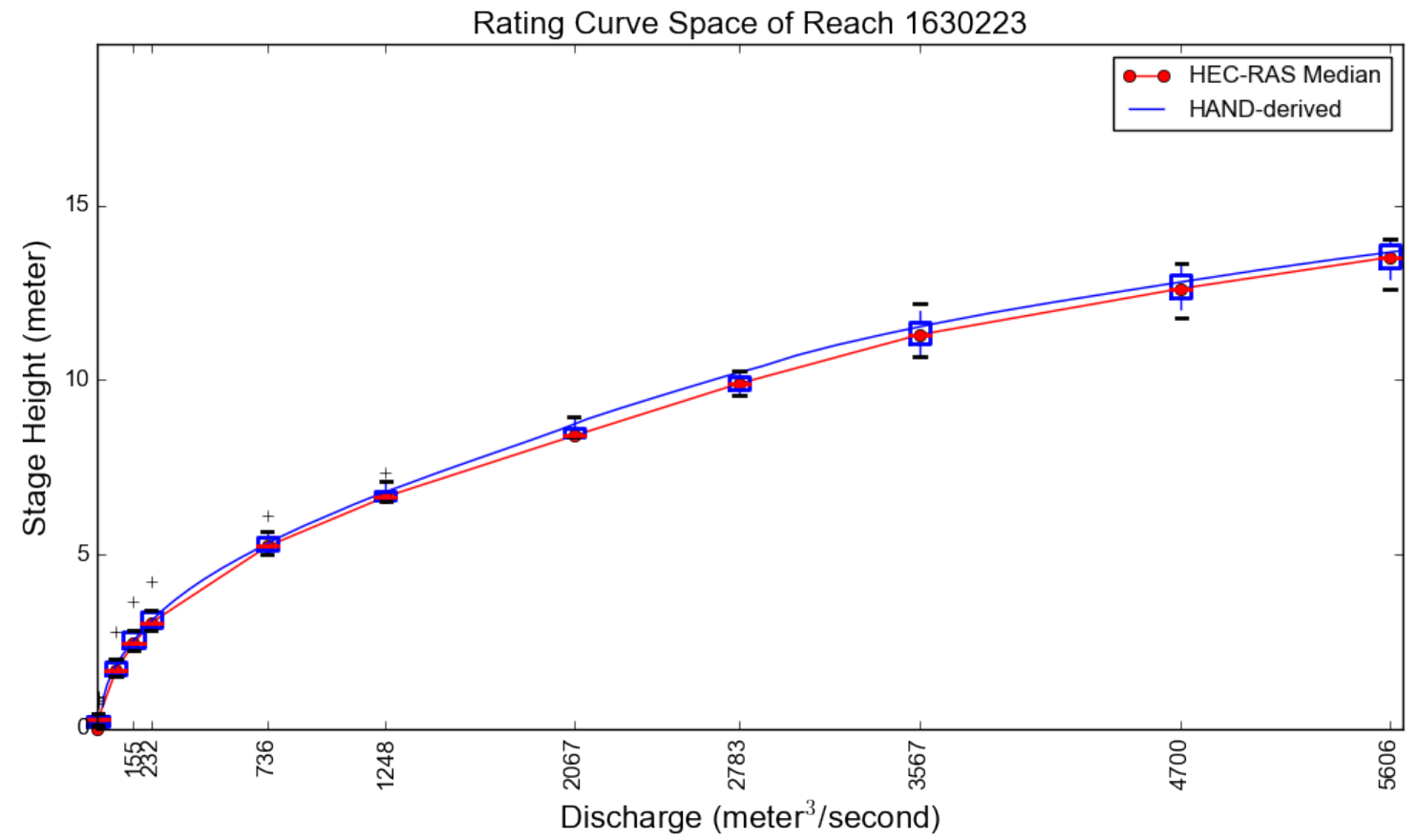

FIGURE 14: Comparison between HAND-derived and RAS-derived rating curves on reach $1630223(n=0.045)$. 


\section{Comparison of Rating Curve and USGS Gage Observations}

To better estimate the performance of HAND-derived synthetic rating curves and the effect of Manning's $n$ calibration on the performance we compared the HANDderived synthetic rating curves with those at USGS stream gages. The Tar River watershed in North Carolina was selected as the test bed (Figure 15). In this watershed, local hydraulic models have been integrated into a sophisticated flood risk information system. Within the domain covered by local models, observed rating curves are collected from nine USGS stream gages. The metric we use to compare the performance of rating curves obtained from multiple approaches is the difference in water depth converted from the 100-year flood discharge. Two types of information collected from local hydraulic models are adopted when we conduct this comparison at each stream gage: the first one is the 100-year flow estimated from flood frequency analyses conducted by local model providers; the second one is the Manning's $n$ range for channel and overbank zone from FEMA flood insurance study reports organized by county (Edgecombe, Franklin, Granville, Halifax, Nash, and Pitt). After we obtained the 100-year discharge at each gage station from the local HEC-RAS model, we first converted it into the corresponding water depth using the gage measured rating curves, then performed another conversion with the HAND-derived rating curve computed with the default Manning's $n$ value 0.05. Finally, we tuned the Manning's $n$ value within the given $n$ range to generate different rating curves and identified the optimal Manning's $n$, which led to a depth closest to USGS gage measurements. 


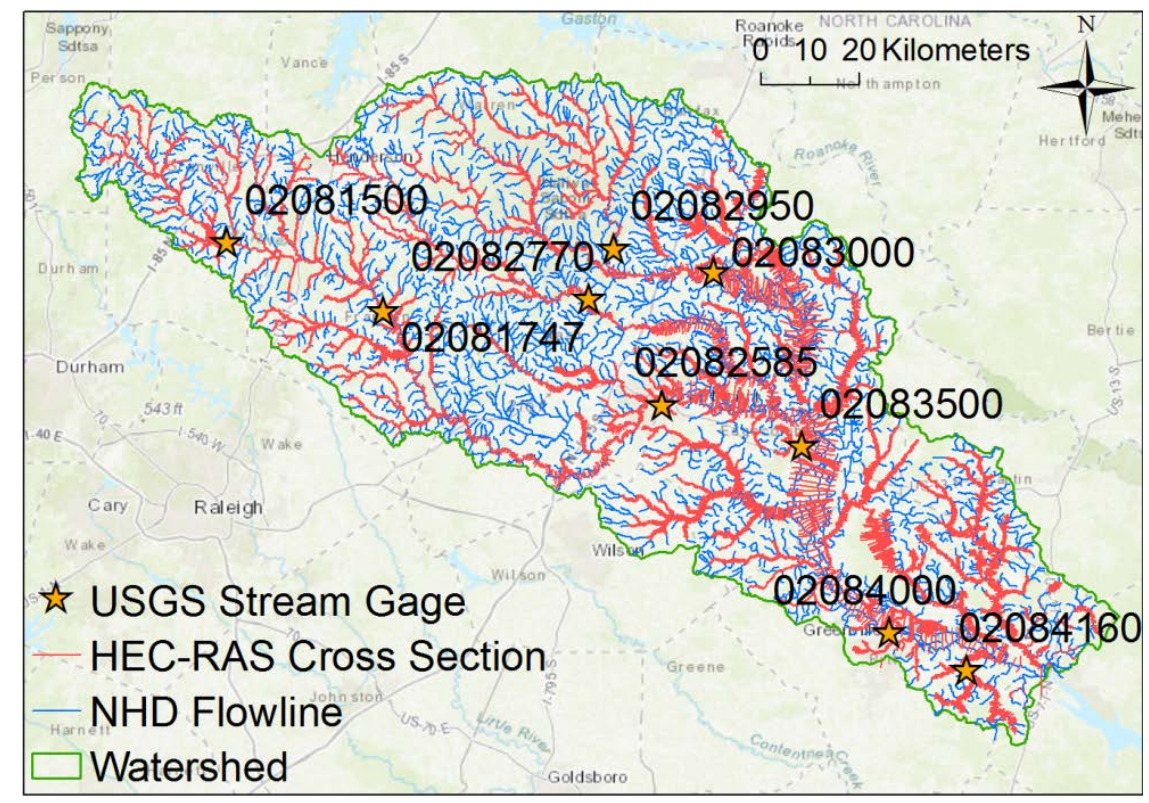

FIGURE 15: USGS stream gages with available measured rating curves in the Tar River watershed.

Table 2: Comparison of centerline water depths corresponding to the 100-year flood discharge converted through the USGS observed rating curve and the HAND-derived rating curve with default Manning's $n$ (0.05) and optimal Manning's $n$. (nchannel: channel zone Manning's $n$ range from FEMA flood insurance studies, nfloodplain: overbank zone

Manning's $n$ range from FEMA flood insurance studies, Q100-year: 100-year flood discharge at given site, $\mathrm{H}_{\text {usgs: }}$ 100-year flood centerline water depth converted using USGS measured rating curve, Hhand-0.05: 100-year flood centerline water depth converted using HAND-derived synthetic rating curve with default Manning's n, Hhand-best: 100-year flood centerline water depth converted using HAND-derived synthetic rating curve with optimal Manning's $n$, nbest: optimal Manning's $n$ value that produces the synthetic rating curve closest to USGS gage measurement)

\begin{tabular}{cccccccc}
\hline $\begin{array}{c}\text { USGS } \\
\text { Site ID }\end{array}$ & $\mathrm{n}_{\text {channel }}$ & $\mathrm{n}_{\text {floodplain }}$ & $\begin{array}{c}\mathrm{Q}_{100-\text { year }} \\
\left(\mathrm{m}^{3} / \mathrm{s}\right)\end{array}$ & $\begin{array}{c}\mathrm{H}_{\text {usgs }} \\
(\mathrm{m})\end{array}$ & $\begin{array}{c}\mathrm{H}_{\text {hand-0.05 }} \\
(\mathrm{m})\end{array}$ & $\begin{array}{c}\mathrm{H}_{\text {hand-best }} \\
(\mathrm{m})\end{array}$ & $\mathrm{n}_{\text {best }}$ \\
\hline 02081500 & $0.03-0.058$ & $0.1-0.17$ & 543 & 6.79 & 6.15 & 6.56 & 0.058 \\
02081747 & $0.03-0.042$ & $0.08-0.15$ & 715 & 7.07 & 8.82 & 7.04 & 0.031 \\
02082585 & $0.025-0.05$ & $0.05-0.16$ & 784 & 8.52 & 7.28 & 8.52 & 0.096 \\
02083500 & $0.025-0.05$ & $0.05-0.16$ & 1334 & 11.41 & 6.75 & 11.39 & 0.123 \\
02084000 & $0.045-0.08$ & $0.06-1$ & 1504 & 7.91 & 8.4 & 7.95 & 0.045 \\
02082770 & $0.042-0.06$ & $0.05-0.15$ & 511 & 5.54 & 3.31 & 5.31 & 0.15 \\
02082950 & $0.044-0.065$ & $0.05-0.16$ & 394 & 7.28 & 6.23 & 7.27 & 0.077 \\
02083000 & $0.04-0.08$ & $0.035-0.2$ & 688 & 5.65 & 4.28 & 5.65 & 0.103 \\
02084160 & $0.045-0.055$ & $0.1-0.165$ & 152 & 2.19 & 1.41 & 2.19 & 0.104 \\
\hline
\end{tabular}



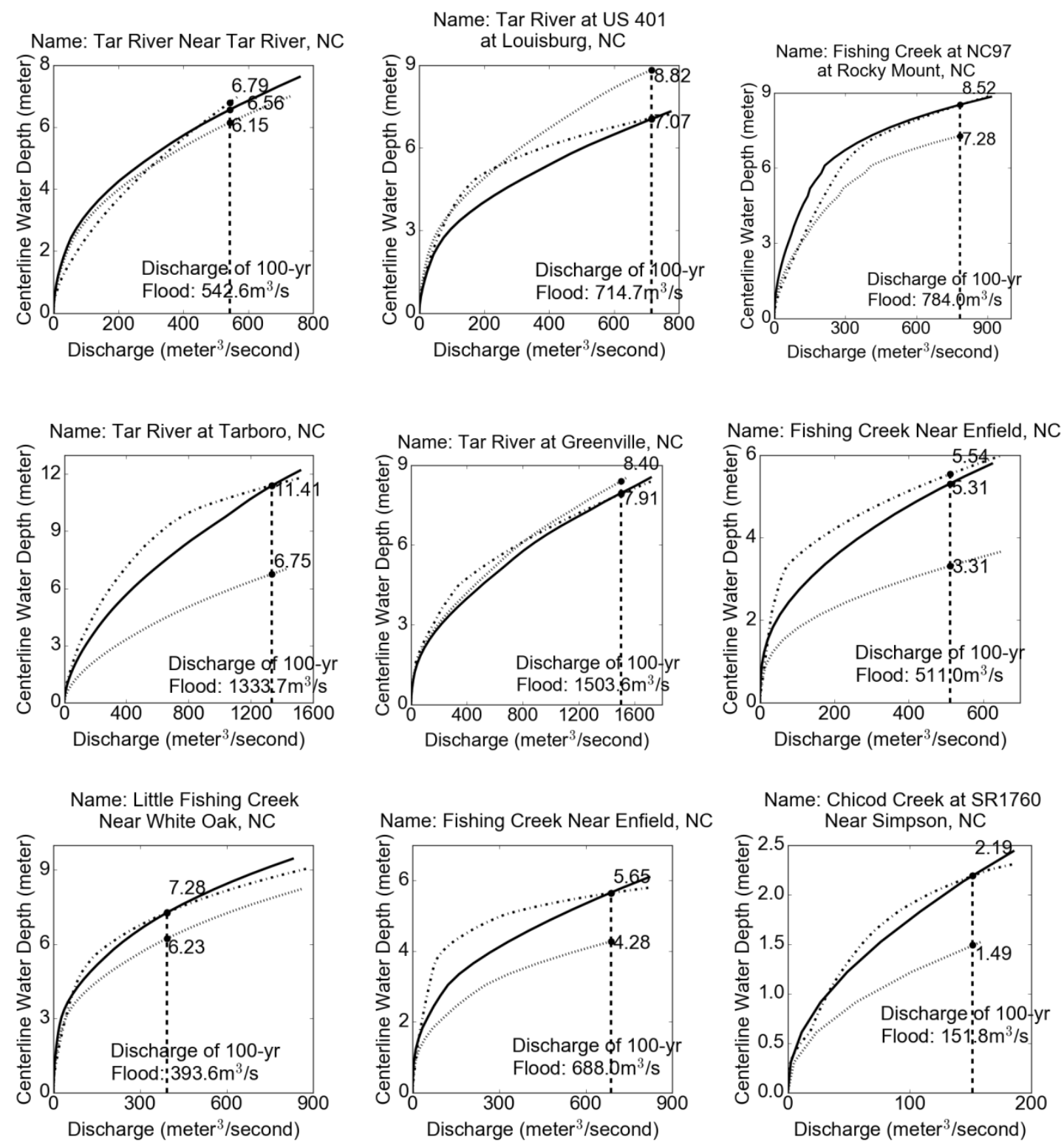

\section{HAND with default Manning's n 0.05 \\ HAND with optimal Manning's $n$}

FIGURE 16: Comparison of measured rating curves and HAND-derived synthetic rating curves at USGS stream gages in the Tar River watershed.

The results (Table 2, Figure 16) show that compared to the observed dischargestage relationships, although synthetic rating curves derived from the HAND raster with a constant Manning's $n$ assigned globally could not reach a significantly high accuracy everywhere, tuning Manning's $n$ within a reasonable range can achieve near-real water depth prediction if more information about the channel roughness condition is available. 
Inundation Extent Validation versus FEMA 100-year Floodplain

Although the estimation of HAND inundation mapping products is not the main focus of this study, we compare the HAND-derived inundation maps with FEMA 100year floodplains to generally demonstrate the effectiveness of our HAND approach when it is applied to inundation mapping practice. The comparison is conducted within the same nine NHD catchments at the Tar River watershed where the stream gages are located. We generate the inundation extent corresponding to the 100-year flood depth obtained from previous analyses. To test how the accuracy of water depth prediction affects the accuracy of inundation mapping extent, we adopt different water depths computed from the observed rating curve and the synthetic rating curve with an uncalibrated Manning’s n value (0.05).

Table 3: Comparison of FEMA 100-year floodplain and HAND-derived inundation extent in Tar River NHD catchments where USGS streamgages are located. (AreafemA: area of FEMA floodplain, Areausgs: area of HAND-derived inundation extent corresponding to the centerline depth predicted from USGS rating curve, AreaInitial: area of HAND-derived inundation extent corresponding to the centerline depth predicted from synthetic rating curve with Manning's $n$ of 0.05, Fusgs \& Cusgs: F Index and C Index computed using Areafema and Areausgs, FInitial \& CInitial: F Index and C Index computed using Areafema and AreaInitial)

\begin{tabular}{cccccccc}
\hline $\begin{array}{c}\text { USGS } \\
\text { Site ID }\end{array}$ & $\begin{array}{c}\text { Area } \\
\left(\mathrm{km}^{2}\right)\end{array}$ & $\begin{array}{c}\text { AreausgS } \\
\left(\mathrm{km}^{2}\right)\end{array}$ & $\begin{array}{c}\text { Area Initial } \\
\left(\mathrm{km}^{2}\right)\end{array}$ & FusGS & CUSGS $_{\text {Unitial }}$ & C Initial \\
\hline 02081500 & 0.16 & 0.15 & 0.14 & 0.90 & 0.99 & 0.93 & 0.98 \\
02081747 & 0.19 & 0.21 & 0.34 & 0.82 & 0.99 & 0.54 & 1.00 \\
02082585 & 1.63 & 1.78 & 1.40 & 0.86 & 0.99 & 0.84 & 0.88 \\
02082770 & 1.88 & 2.26 & 1.64 & 0.80 & 1.00 & 0.91 & 0.92 \\
02082950 & 1.39 & 1.64 & 1.33 & 0.79 & 1.00 & 0.91 & 0.97 \\
02083000 & 1.24 & 1.27 & 1.18 & 0.94 & 1.00 & 0.97 & 0.98 \\
02083500 & 0.35 & 0.51 & 0.46 & 0.65 & 1.00 & 0.66 & 0.95 \\
02084000 & 0.49 & 0.53 & 0.56 & 0.87 & 1.00 & 0.82 & 1.00 \\
02084160 & 0.37 & 0.27 & 0.22 & 0.81 & 0.82 & 0.67 & 0.67 \\
\hline
\end{tabular}



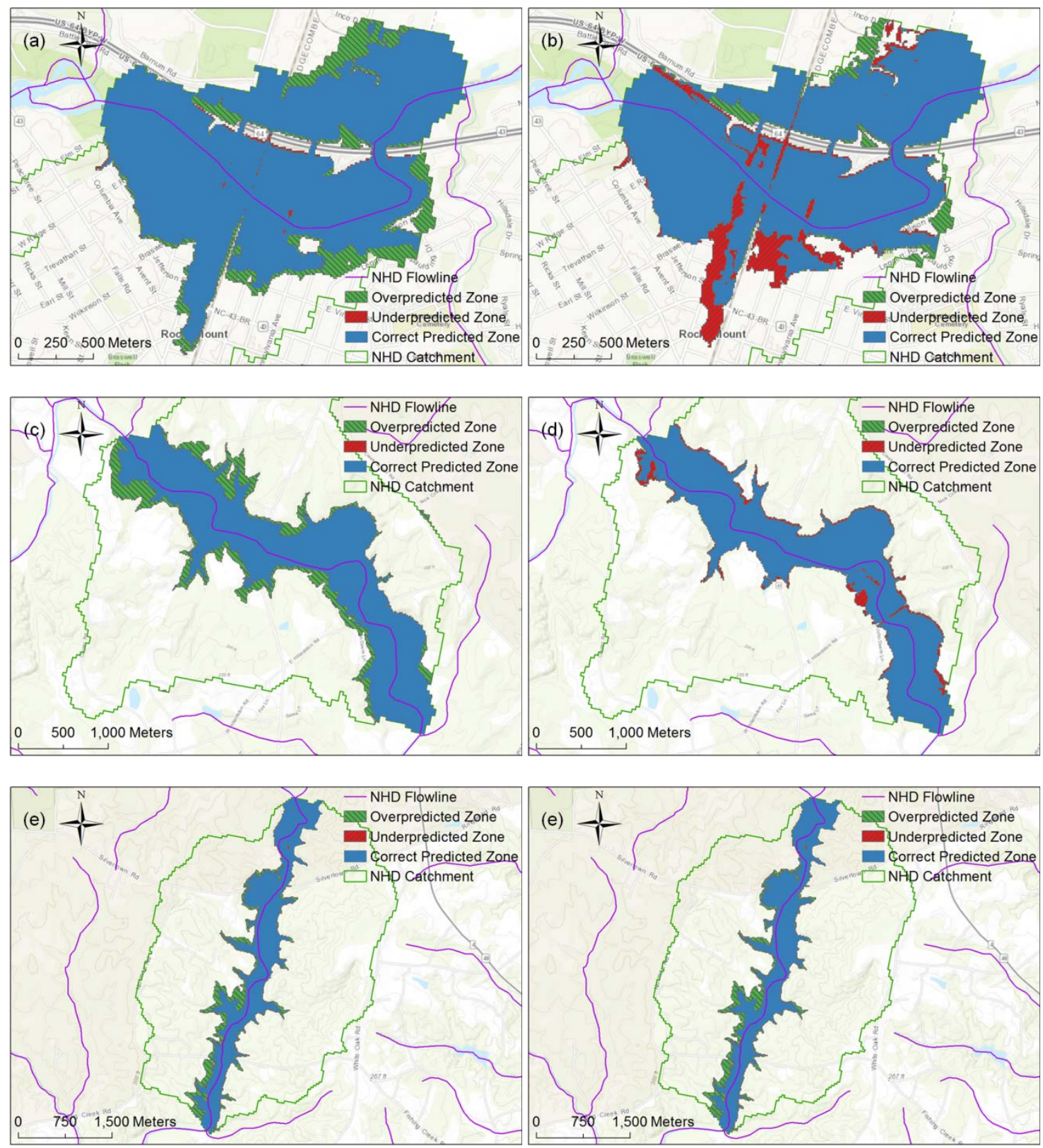

FIGURE 17: Comparison of FEMA 100-year floodplain and HAND-derived inundation extent in Tar River NHD catchments where USGS stream gages are located. (Catchments with top three inundated area size are selected to present, (a)(b): USGS gage 02082585, (c)(d):USGS gage 02082770, (e)(f):USGS gage 02082950. (a)(c)(e) show HAND the inundation extent generated with the water depth predicted from USGS observed rating curves, (b)(d)(f) show the HAND inundation extent generated with the water depth predicted from HAND-derived synthetic rating curves with Manning's $n$ of 0.05)

The results in Table 3 and Figure 17 show that in general, the inundation extent 
produced with the HAND approach is able to capture the majority of FEMA floodplain, even without a calibration of the Manning's $n$ coefficient. Due to the absence of the bathymetric portion, the water depth computed from the terrain data with our HAND approach is often higher than the actual water depth. Therefore, a more accurate prediction of flood depth does not necessarily lead to a better estimation of the inundation extent with our approach. Instead, a slight over-prediction of inundation extent is detected at many sites. We also observed that the HAND inundation mapping method performs better in the hilly, rural catchments where the flood routing process is controlled by the topographic setting, compared to the flat, urbanized catchments where artificial structures significantly affects the hydrodynamic process. We are exploring more sophisticated physical methods to capture the mass and momentum exchange within the affected flood zones.

\section{DISCUSSION}

This paper has presented a new method for the determination of reach average hydraulic properties from a digital elevation model based on the Height Above Nearest Drainage (HAND) approach. The comparison to HEC-RAS cross sections showed that the method can produce reasonable results. This finding holds promise, as the method can be fully automated and is based on readily available national data and can thus be applied rapidly across the whole country reducing the need for detailed cross sectionbased flood inundation mapping. We believe that this method has the potential to support national scale modeling, such as the National Water Model.

There are, however, some limitations to our approach. We assumed, for example, that the input DEM represents the shape of the river channel and comparison with HECRAS showed that adjustments of the base elevation may be needed in certain cases. We expect that as DEMs are improved, especially if and when channel bed bathymetry is obtained from water penetrating lidar or sonic depth measurement, the need for such adjustments may be reduced and the results from the HAND method improved. We also acknowledge the preliminary and approximate nature of the proposed method, particularly in areas where artificial hydraulic structures or momentum interaction between channel and floodplain controls the propagation of flood waves. Therefore, we 
suggest that this method should be used primarily as a screening tool for identifying locations where more detailed studies are warranted.

We illustrated how the pit filling process, needed to ensure a hydrologically conditioned DEM (where each grid cell drains to the edge of the domain), can result in incorrect DEM values along the streams. Some of these values occur behind barriers due to artifacts in the DEM production process, for example the DEM representation of the elevation of road/railway crossings and not of the elevation beneath these crossings at which water passes. We are investigating ways to use high resolution hydrography information (e.g. NHD HR, nominally at 1:24,000 scale (ftp://rockyftp.cr.usgs.gov/vdelivery/Datasets/Staged/Hydrography/NHD/National/HighR esolution/), that represents flow lines with greater fidelity than NHDPlus, to adjust the DEM so that elevation is non increasing along hydrographically mapped flow lines. This information provides the capability to go through barriers where the hydrography indicates that the flow crosses the barrier, partially alleviating this problem. We are also investigating using geodesic approaches to map flow paths (e.g., Passalacqua et al., 2010; Sangireddy et al., 2016) to overcome barriers more automatically without the need for hydrographic mapping.

We showed how hydrography, notably the NHDplus medium resolution hydrography used in the National Water Model can be misaligned with valley paths in a DEM. The HAND approach follows flow directions downslope and requires that the streams are aligned with the DEM. Using the NHDPlus flowlines directly would have resulted in spurious results for the area (as illustrated in Figures 3 and 4); this finding motivated our use of the DEM stream delineation approach starting from NHDPlus channel heads. However, even with this approach, a one to one mapping between stream segments in the DEM delineated network and NHDPlus is not guaranteed and areas draining to DEM stream segments may not align exactly with NHDPlus catchments, resulting in errors around the edges when clipping the HAND raster based on the NHDPlus catchment boundaries. There is thus a need, in national datasets, for better alignment and reconciliation of elevation and hydrography representations of streams. An example of ongoing effort is the NHDPlusHR (Viger et al., 2016).

Channel properties are currently organized by reach and a uniform water depth is 
assigned to a reach during the inundation mapping process. Sometimes reaches are quite long and assuming a uniform depth is unreasonable. It is possible to split reaches into shorter segments, but we leave to future work the exploration of the best length to use. The optimal distance between cross sections in 1D hydraulic modelling has been shown to be proportional to the bankfull width (Samuels, 1990; Castellarin, 2009); adding extra cross sections within the optimal spacing decreases the accuracy of the simulation due to rounding errors (Castellarin, 2009). If the segments of a reach can be specified and exported during the HAND computational process, these new profiles across the stream cells have a potential to replace the traditional cross sections used in 1-D hydraulic models. Organizing hydraulic properties in a segment unit smaller than a reach also has the potential to help resolve the instability problem in large-scale hydraulic models when a sudden channel shape change happens at a river confluence. The validation of HAND channel geometry properties through the comparison with HEC-RAS-derived reachaverage channel should be extended to a larger sample size. To ensure comprehensiveness, this sample should cover reaches of different stream orders and with different physiographic settings.

To evaluate the accuracy of our inundation extent, we compared the 100-year inundation extent with FEMA 100-year floodplains. We chose FEMA maps as reference because they are the officially approved source of information on inundation extent and have large spatial coverage. We acknowledge, however, that great uncertainty exists in these maps and suggest that more accurate ground truth information should be used to test inundation mapping results in the future, for example the inundation extent library provided by the NWS Advanced Hydrologic Prediction Service (AHPS). In this library, a separate inundation extent is generated for different water depths with an interval of $1 \mathrm{ft}$ via hydrodynamic simulation. In should be noted that these maps are currently only available for 133 forecast sites across the continental US.

With our proposed approach we are able to generate a library of inundation extents based on the HAND raster. In the future, a comparison of the inundation extent generated from the HAND raster and the current inundation extent library (where available) could be performed to quantify the difference between these two groups. The results of this comparison could be used to adjust the HAND inundation extents and use 
them to fill the gap where other information is not available.

A generic way to evaluate channel and floodplain roughness values from land cover information or any other instructive variables would be helpful to improve the accuracy of the HAND rating curves. A calibration of the roughness coefficient for each individual river segment would require significant effort without significantly improving the final results, compared to a regional-scale estimation. For the purpose of approximate inundation mapping, our results show that the most accurate water depth conversion does not necessarily result in the best estimation of inundation extents because of the absence of channel bathymetric details in the input terrain data and uncertainties associated with other assumptions in the process. The method here proposed is able to generate reasonable approximate inundation extents with channel roughness characteristics estimated based on large-scale land cover information. Future research could identify ways to improve the estimation of the roughness coefficient. For example, if the bankfull depth information of all the rivers in a large-scale network could be derived from the geometry data, a compound uniform flow equation could be implemented, instead of applying a single Manning's equation to all water levels in a reach, to better describe the hydraulics when the water level reaches the floodplain. Also, the hydraulic conductance underestimation problem of empirical hydraulic equations at high flow condition needs to be considered. If a large-scale hydrodynamic model such as SPRNT (Liu and Hodges, 2014) were to be used, rating curves could be generated from the simulations with HAND river geometry information fed to the model. Note that, if a different method were to be employed to determine the water depth in the channel, such as by direct observation or by using a solution of the full Saint Venant equations (SPRNT), then the hydraulic geometry data and the HAND raster could be used to produce an inundation map without the need for synthetic rating curves.

\section{CONCLUSION}

In this paper, a workflow for computing river geometry and estimating channel reach rating curves based on DEM derived Height Above Nearest Drainage (HAND) was presented. The method was illustrated for NHDPlus reaches of the Blanco River 
watershed using the $1 / 3$ arc sec USGS 3DEP Elevation dataset DEM. The workflow requires as input a DEM, the channel heads (or a stream network from which they can be extracted), and a Manning's n value. The hydraulic geometry properties and rating curve derived from the HAND approach were shown to be generally consistent with similar information derived from more traditional cross sections and HEC-RAS hydraulic modeling, which require a much more labor and data intensive process. Issues related to DEM fidelity and the need for adjustments in the base elevation were identified and discussed. Calibration to determine an optimal Manning's n roughness parameter produced a value very close to the value used in HEC-RAS modeling, further validating the approach. Overall, our proposed method was shown to hold promise for supporting quantitative hydraulic modeling at continental scale using readily available national datasets. A companion paper (Liu et al., 2018) applies this approach to nationally available data using high performance computing.

Our method has attracted interest from the community, industry, and government agencies. Starting with the 2016 National Flood Interoperability Experiment, researchers have been working extensively to test the performance of our inundation approach against other methods [Afshari et al., 2018; Zhang et al., 2018]. Esri has integrated different components of our workflow into the latest ArcHydro toolbox. The NOAA National Water Center implemented the HAND workflow during Hurricane Harvey to produce real-time flood maps for over 60,000 kilometers of streams and river in Southeast Texas. In 2018, NOAA proposed to implement the HAND inundation mapping operationally for the West Gulf forecast region. Although limitations exist in our method due to the terrain-only consideration and the one-dimensional steady flow assumption, we think it is a valid approach for approximate inundation mapping especially in those areas where detailed hydraulic studies are not available. We encourage readers to test our method under different flow and terrain scenarios to achieve a comprehensive understanding of its performance and limitations.

\section{ACKNOWLEDGEMENTS}

This research has been supported in part by Texas Division of Emergency Management under grant number 26-3215-2275 and Consortium of Universities for the 
Advancement of Hydrologic Science, Inc. (CUAHSI). Part of this study was conducted during the 2016 National Water Center Innovators Program: Summer Institute at the National Water Center. Thanks to Fort Worth District of US Army Corps of Engineers for providing the Blanco River HEC-RAS model. Thanks to the Editor, Associate Editor, and three reviewers for insightful comments which significantly improved this work.

\section{LITERATURE CITED}

Allen, George H., and Tamlin M. Pavelsky, 2015. Patterns of river width and surface area revealed by the satellite-derived North American River Width data set. Geophysical Research Letters 42(2): 395-402. DOI: 10.1002/2014GL062764.

Andreadis, Konstantinos M., Guy J.-P. Schumann, and Tamlin M. Pavelsky, 2013. A simple global river bankfull width and depth database. Water Resources Research 49(10): 71647168. DOI: 10.1002/wrcr.20440.

Apel, Heiko, G. T. Aronica, H. Kreibich, and A. H. Thieken, 2009. Flood risk analyses-how detailed do we need to be?. Natural Hazards 49(1): 79-98. DOI: 10.1007/s11069-008-92778

Afshari, Shahab, A. A. Tavakoly, M. A. Rajib, X. Zheng, M. L. Follum, E. Omranian, and B. M. Fekete, 2018. Comparison of new generation low-complexity flood inundation mapping tools with a hydrodynamic model. Journal of Hydrology 556: 539-556. DOI: 10.1016/j.jhydrol.2017.11.036

Castellarin, Attilio, Giuliano Di Baldassarre, Paul D. Bates, and Armando Brath, 2009. Optimal cross-sectional spacing in Preissmann scheme 1D hydrodynamic models. Journal of Hydraulic Engineering 135(2): 96-105. DOI: 10.1061/(ASCE)0733-9429(2009)135:2(96)

Garambois, Pierre-André, Stéphane Calmant, Hélène Roux, Adrien Paris, Jérôme Monnier, Pascal Finaud-Guyot, Amanda Samine Montazem, and Joecila Santos da Silva, 2017. Hydraulic visibility: Using satellite altimetry to parameterize a hydraulic model of an ungauged reach of a braided river. Hydrological Processes 31(4): 756-767. DOI: 10.1002/hyp.11033

Gesch, D.B., Oimoen, M.J., and Evans, G.A., 2014. Accuracy assessment of the U.S. Geological Survey National Elevation Dataset, and comparison with other large-area elevation datasets—SRTM and ASTER: U.S. Geological Survey Open-File Report 2014-1008, 10 p., DOI: 10.3133/ofr20141008.

Getirana, Augusto C. V., Boone, Aaron Boone, Dai Yamazaki, Nelly Mognard, 2013. Automatic parameterization of a flow routing scheme driven by radar altimetry data: Evaluation in the Amazon basin. Water Resources Research 49(1): 614-629. DOI: 10.1002/wrcr.20077

Hallegatte, Stephane, Colin Green, Robert J. Nicholls, and Jan Corfee-Morlot, 2013. Future flood losses in major coastal cities. Nature climate change 3(9): 802-806. DOI: 10.1038/nclimate1979

Knox, James C., 1993. Large increases in flood magnitude in response to modest changes in climate. Nature 361(6411): 430-432. DOI: 10.1038/361430a0

Leopold, Luna Bergere, and Thomas Maddock, 1953. The hydraulic geometry of stream channels 
and some physiographic implications (No. 252). US Government Printing Office.

Liu, Frank, and Ben R. Hodges, 2014. Applying microprocessor analysis methods to river network modelling. Environmental Modelling \& Software 52: 234-252. DOI: 10.1016/j.envsoft.2013.09.013

Liu, Yan Y., David R. Maidment, David G. Tarboton, Xing Zheng, and Shaowen Wang, 2018. A CyberGIS Integration and Computation Framework for High-Resolution Continental-Scale Flood Inundation Mapping. Journal of the American Water Resources Association (JAWRA), Draft for review.

Maidment, David R., 1992. Handbook of hydrology. McGraw-Hill, New York, ISBN-13: 9780070397323

Maidment, David R., 2016. Conceptual Framework for the National Flood Interoperability Experiment. Journal of the American Water Resources Association (JAWRA) 53(2): 245-257. DOI: $10.1111 / 1752-1688.12474$

Milly, P. Christopher D., Richard T. Wetherald, K. A. Dunne, and Thomas L. Delworth, 2002. Increasing risk of great floods in a changing climate. Nature 415(6871): 514-517. DOI: $10.1038 / 415514 a$

Nobre, Antonio Donato, Luz Adriana Cuartas, Martin G. Hodnett, Camilo Daleles Rennó, G. Rodrigues, A. Silveira, Maarten J. Waterloo and S. Saleska, 2011. Height Above the Nearest Drainage-a hydrologically relevant new terrain model. Journal of Hydrology 404(1): 13-29. DOI: 10.1016/j.jhydrol.2011.03.051

Nobre, Antonio Donato, Luz Adriana Cuartas, Marcos Rodrigo Momo, Dirceu Luís Severo, Adilson Pinheiro, and Carlos Afonso Nobre, 2016. HAND contour: A new proxy predictor of inundation extent. Hydrological Processes 30(2): 320-333. DOI: 10.1002/hyp.10581

Noji, E. K., 1991. Natural disasters. Critical care clinics 7(2): 271-292.

O'Callaghan, John F., and David M. Mark, 1984. The extraction of drainage networks from digital elevation data. Computer vision, graphics, and image processing 28(3): 323-344. DOI: 10.1016/S0734-189X(84)80011-0

Ohl, Christopher A., and Sue Tapsell, 2000. Flooding and human health: the dangers posed are not always obvious. British Medical Journal 321(7270): 1167-1167.

Paris, Adrien, Rodrigo Dias de Paiva, Joecila Santos da Silva, Daniel Medeiros Moreira, Stephane Calmant, Pierre-André Garambois, Walter Collischonn, Marie-Paule Bonnet, and Frederique Seyler, 2016. Stage-discharge rating curves based on satellite altimetry and modeled discharge in the Amazon basin. Water Resources Research 52(5): 3787-3814. DOI: 10.1002/2014WR016618.

Passalacqua, Paola, Tien Do Trung, Efi Foufoula-Georgiou, Guillermo Sapiro, and William E. Dietrich, 2010. A geometric framework for channel network extraction from lidar: Nonlinear diffusion and geodesic paths. Journal of Geophysical Research Earth Surface. 115: F01002. DOI: 10.1029/2009JF001254

Pavelsky, Tamlin M., and Laurence C. Smith, 2008. RivWidth: A software tool for the calculation of river widths from remotely sensed imagery. IEEE Geoscience and Remote Sensing Letters 5(1): 70-73. DOI: 10.1109/LGRS.2007.908305

Rennó, Camilo Daleles, Antonio Donato Nobre, Luz Adriana Cuartas, João Vianei Soares, Martin G. Hodnett, Javier Tomasella, and Maarten J. Waterloo, 2008. HAND, a new terrain descriptor using SRTM-DEM: Mapping terra-firme rainforest environments in Amazonia. 
Remote Sensing of Environment 112(9): 3469-3481. DOI: 10.1016/j.rse.2008.03.018

Rodda, Harvey J., 2005. The development and application of a flood risk model for the Czech Republic. Natural hazards 36(1-2): 207-220. DOI: 10.1007/s11069-004-4549-4

Samuels, P. G., 1990. Cross-section location in 1-D models. In: 2nd International Conference on River Flood Hydraulics. Wiley, Chichester, pp. 339-350.

Sangireddy, Harish, Colin P. Stark, Anna Kladzyk, Paola Passalacqua, 2016. GeoNet: An open source software for the automatic and objective extraction of channel heads, channel network, and channel morphology from high resolution topography data, Environmental Modeling and Software. 83: 58-73. DOI: 10.1016/j.envsoft.2016.04.026

Tarboton, David G., Rafael L. Bras and Ignacio Rodriguez-Iturbe, 1991. On the Extraction of Channel Networks from Digital Elevation Data. Hydrologic Processes 5(1): 81-100. DOI: 10.1002/hyp.3360050107

Tarboton, David G., Rafael L. Bras and Ignacio Rodriguez-Iturbe, 1992. A Physical Basis for Drainage Density. Geomorphology 5(1/2): 59-76. DOI: 10.1016/0169-555X(92)90058-V

Tarboton, David G., 1997. A new method for the determination of flow directions and upslope areas in grid digital elevation models. Water Resources Research 33(2): 309-319. DOI: 10.1029/96WR03137

Tarboton, David G. and Daniel P. Ames, 2001. Advances in the mapping of flow networks from digital elevation data. In: Bridging the Gap: Meeting the World's Water and Environmental Resources Challenges. World Water and Environmental Resources Congress, Orlando, Florida, pp. 1-10. DOI: 10.1061/40569(2001)166

Tarboton, David G., 2016. Terrain Analysis Using Digital Elevation Models (TauDEM). Utah Water Research Laboratory. Utah State University. http://hydrology.usu.edu/taudem. accessed 9/5/2016.

Tesfa, Teklu K., David G. Tarboton, Daniel W. Watson, Kimberly A. T. Schreuders, Matthew E. Baker and Robert M. Wallace, 2011. Extraction of hydrological proximity measures from DEMs using parallel processing. Environmental Modelling \& Software 26(12): 1696-1709. DOI: 10.1016/j.envsoft.2011.07.018

Viger, Roland J., Alan Rea, Jeffrey D. Simley and Karen M. Hanson, 2016. NHDPlusHR: A National Geospatial Framework for Surface-Water Information, Journal of the American Water Resources Association (JAWRA) 52(4): 901-905. DOI: 10.1111/1752-1688.12429

Yamazaki, Dai, Fiachra O'Loughlin, Mark A. Trigg, Zachary F. Miller, Tamlin M. Pavelsky, and Paul D. Bates, 2014. Development of the global width database for large rivers. Water Resources Research 50(4): 3467-3480. DOI: 10.1002/2013WR014664

Zhang, Jiaqi, Y. Huang, D. Munasinghe,, Z. Fang, Y. Tsang, and S. Cohen, 2018. Comparative Analysis of Inundation Mapping Approaches for the 2016 Flood in the Brazos River, Texas. Journal of the American Water Resources Association (JAWRA) 1-14. DOI: 10.1111/1752-1688.12623

Zheng, X., 2015. Hydraulic fabric: an information framework for river channel cross section data. Master Dissertation, University of Texas at Austin, Austin, Texas 